\title{
Transcriptome profiling provides insights into molecular mechanism in Peanut semi- dwarf mutant
}

Fengdan Guo ${ }^{1,2+}$, Junjie Ma ${ }^{2,3+}$, Lei Hou ${ }^{1,2}$, Suhua Shi ${ }^{1,2}$, Jinbo Sun ${ }^{1,2}$, Guanghui Li ${ }^{2}$, Chuanzhi Zhao ${ }^{1,2}$, Han Xia ${ }^{1,2}$, Shuzhen Zhao ${ }^{1,2}$, Xingjun Wang ${ }^{1,2,3^{*}}$ (i) and Yanxiu Zhao ${ }^{1 *}$

\begin{abstract}
Background: Plant height, mainly decided by main stem height, is the major agronomic trait and closely correlated to crop yield. A number of studies had been conducted on model plants and crops to understand the molecular and genetic basis of plant height. However, little is known on the molecular mechanisms of peanut main stem height.

Results: In this study, a semi-dwarf peanut mutant was identified from ${ }^{60} \mathrm{Co} \gamma$-ray induced mutant population and designated as semi-dwarf mutant 2 (sdm2). The height of sdm2 was only $59.3 \%$ of its wild line Fenghua 1 (FH1) at the mature stage. The sdm2 has less internode number and short internode length to compare with $\mathrm{FH} 1$. Gene expression profiles of stem and leaf from both sdm2 and FH1 were analyzed using high throughput RNA sequencing. The differentially expressed genes (DEGs) were involved in hormone biosynthesis and signaling pathways, cell wall synthetic and metabolic pathways. BR, GA and IAA biosynthesis and signal transduction pathways were significantly enriched. The expression of several genes in BR biosynthesis and signaling were found to be significantly down-regulated in sdm2 as compared to FH1. Many transcription factors encoding genes were identified as DEGs.

Conclusions: A large number of genes were found differentially expressed between sdm2 and $\mathrm{FH}$. These results provide useful information for uncovering the molecular mechanism regulating peanut stem height. It could facilitate identification of causal genes for breeding peanut varieties with semi-dwarf phenotype.
\end{abstract}

Keywords: Peanut (Arachis hypogaea L.), Main stem height, RNA-seq, Cell wall related genes, Hormones, Transcription factors

\section{Background}

Plant height, a decisive factor of plant architecture, is an important agronomic trait which contributes to crop yield. Plant height is highly associated with rain or wind caused lodging and the utilization of dwarf and semi-dwarf plants could be a way to reduce the risk. Elongation of main stem

\footnotetext{
* Correspondence: xingjunw@hotmail.com; zhaoyx@sdnu.edu.cn

${ }^{\dagger}$ Fengdan Guo and Junjie Ma contributed equally to this work.

'College of Life Science, Shandong Normal University, Jinan, People's Republic of China

Full list of author information is available at the end of the article
}

is the main limiting factor of plant height. The breeding of semi-dwarf rice and wheat varieties in 1960s gave rise to the first 'green revolution' and increased grain yields significantly [1, 2]. Peanut (Arachis hypogaea L.) is an important oil crop in the world. In China, most of cultivated peanut varieties are erect. To prevent overgrowth and lodging, growth inhibitory substances like paclobutrazol and uniconazole are usually applied 2 3 times during the growth season. Therefore, studying the underlying molecular mechanism controlling main stem height and

(c) The Author(s). 2020 Open Access This article is licensed under a Creative Commons Attribution 4.0 International License, which permits use, sharing, adaptation, distribution and reproduction in any medium or format, as long as you give appropriate credit to the original author(s) and the source, provide a link to the Creative Commons licence, and indicate if changes were made. The images or other third party material in this article are included in the article's Creative Commons licence, unless indicated otherwise in a credit line to the material. If material is not included in the article's Creative Commons licence and your intended use is not permitted by statutory regulation or exceeds the permitted use, you will need to obtain permission directly from the copyright holder. To view a copy of this licence, visit http://creativecommons.org/licenses/by/4.0/ The Creative Commons Public Domain Dedication waiver (http://creativecommons.org/publicdomain/zero/1.0/) applies to the data made available in this article, unless otherwise stated in a credit line to the data. 
developing semi-dwarf peanut variety are of great significance.

Stem elongation is determined by cell growth including cell division and cell expansion. The dynamic variation of plant cell wall is critical in these processes [3]. The cellulose synthase super-family containing cellulose synthases (CesA) and cellulose synthase-like genes (CSL) is very important in cell-wall biogenesis and remodeling. CesA or CSL mutation in plants resulted in a dwarf phenotype with short internode or hypocotyl and small leaves [4-8]. Cell wall extensibility controls the rate of plant cell growth, especially cell expansion [9]. Expansins are plant cell-wall loosening proteins which promote cell enlargement by influencing cell wall extensibility and are essential in many critical developmental processes [10]. Suppression of expansin genes resulted in small, curled leaves, reduced plant height and early flowering [11-14]. Besides expansins, xyloglucanendotransglucosylase/ endohydrolases (XTHs) were also suggested to regulated cell wall loosening $[3,15]$. XTHs catalyze the endo cleavage of xyloglucan polymers and subsequent restructuring, which allow cellulose microfibrils moving along with the cell expansion or elongation process [16-18]. EGases (endo-1,4- $\beta$-glucanases) have been proposed to modify hemicellulose network, and were involved in processes that require cell wall weakening, including cell elongation, organ abscission, and fruit softening [19].

A number of mutants with deficiencies in phytohormone biosynthesis and signal transduction displayed dwarf phenotype [20-24]. Extensive studies showed that most of the dwarf phenotype of plants were associated with gibberellins (GAs) and brassinosteroids (BRs), and a few were caused by auxin (IAA) or strigolactone (SL) [9]. Two "Green Revolution" genes, $s d 1$ and Rht, which encoded GA 20-oxidases and DELLA protein were cloned from rice and wheat, respectively $[1,2,25,26]$. Later, several key genes controlling plant height have been identified. GID1 (GA-insensitive dwarf1) is the GA receptor, and its mutant gid1 in rice showed dwarf phenotype [27]. GA3-oxidases (GA3ox) catalyze the synthesis of bioactive GAs and GA2-oxidases (GA2ox) convert excess GAs to inactive forms. GA3ox deletion and GA2ox overexpression both reduced the plant height $[28,29]$.

Mutants of BR signaling related genes, for examples, the deetiolated (det) [30], diminuto (dim) [31], constitutive photomorphogenesis and dwarfism (cpd) [23] and dwarf4 (dwf4) [32] are all dwarf. DIM was also referred to as DWF1 or CBB1, could convert 24-methylenecholesterol to campesterol $[31,33]$. DET2 was shown to encode a putative steroid $5 \alpha$-reductase [34, 35]. CPD and DWF4 were members of cytochrome P450 family, encoding a putative C-3 oxidase and 22a-hydroxylase, respectively [32, 36]. BRI1 (Brassinosteroid Insensitive 1) is the membrane- localized BR receptor [37-39]. The bri1 mutant displayed severely dwarf phenotype and reduced apical dominance [40]. BAK1 (BRI1-Associated Receptor Kinase 1) is coreceptor of BRI1 and can trigger sequential transphosphorylation of BRI1/BAK1 receptor kinase complex [4143]. The null allele of BAK1 displayed a semi-dwarf phenotype and reduced sensitivity to BRs. BIN2 plays a negative regulatory role in BR signaling and its gain-offunction mutant showed the phenotype similar to BRdeficient and BR-response mutants [44]. BES1 and BZR1 are two bHLH transcription factors, and they can directly bind to target gene promoters together with other transcription regulators to activate BR target gene expression [24, 45-48].

Auxin polar transport is critical in regulating the whole progress of plant growth and development [49]. AUX1/LAX family, PIN family and ABCB subfamily are three classes of polar auxin transporters. MDR (Multidrug Resistance) genes encode P-glycoproteins and belong to subfamily B of ATP-binding cassette (ABCB). The atmdr1 mutants were defective in basipetal auxin transport and shorter than wild-type plants [50]. SAUR (Small Auxin up RNA) genes, the largest family of auxin-responsive genes, functioned as positive effectors of cell expansion and were up-regulated in auxinmediated cell elongation [51-53].

Many transcription factors are important regulators of plant height. SHORT INTERNODES (SHI) gene is a negative regulator of GA response and its overexpression mutant shi showed a dwarf phenotype similar to mutants defective in GA biosynthesis or response [54]. WRKY46/54/70 could be activated by BRs and were cofactors of BES1 to modulate BR target genes [55]. PACLOBUTRAZOL RESISTANT (PRE) is a positive regulator of cell elongation which can be activated by BRs, GAs and repressed by light [56, 57]. PRE together with IBH1, HBI1 and ACE constitute a triantagonistic cascade module which integrate hormonal and environmental signals to regulate cell elongation [58-60].

In peanut, genetic basis underlying plant height remains unclear. Some studies to identify QTLs for plant height have been conducted in peanut. Huang et al. (2016) constructed a high-density genetic linkage map containing 1219 mapped loci using a recombinant inbred line (RIL) population and identified 18 QTLs for plant height [61]. Li et al. (2017) detected 11 QTLs for main stem height using a RIL population [62]. Using two RIL populations, Lv et al. (2018) detected 11 QTLs for plant height. Among which, two QTLs from these two populations were co-localized in a physical interval of 3.4 Mb on A09 [63]. However, no gene closely related to plant height has been cloned in peanut until now.

In the previous research, we built a mutant library through ${ }^{60} \mathrm{Co}$ radiation. Among which, two mutants 
displayed semi-dwarf phenotype. In this study, genomewide gene expression profiling of stem and leaf from $s d m 2$ was conducted to understand the underlying regulation network of main stem height in peanut. The expression of several genes involved in biosynthesis and signal transduction of BRs and GAs were drastically altered in $s d m 2$. Accordingly, the downstream genes related to cell wall biogenesis and remodeling were also changed at the transcriptional level.

\section{Results}

\section{Phenotype characteristics of peanut dwarf mutant}

The main stem height of $s d m 2$ is significantly shorter than that of FH1 $(P<0.01)$ (Fig. 1a). We measured the main stem height of mutant and FH1 grown in the experimental farm every 2 weeks during the vegetative growing stage. Results showed that during the first 2 weeks, main stem height between $s d m 2$ and FH1 had no obviously difference. At 28 DAP (days after planting), main stem height of $s d m 2$ was significantly shorter than that of FH1 $(P<0.01)$. In the following developmental stages, the height difference between $s d m 2$ and FH1 became more and more obvious. At $84 \mathrm{DAP}$, the $s d m 2$ was $15.9 \mathrm{~cm}$ in height, only about $60 \%$ of FH1 $(26.8 \mathrm{~cm})$ (Fig. 1b). The leaf of $s d m 2$ was smaller, thicker and dark green in color, and showed delayed senescence compare to that of FH1. At harvest time, the number of internodes of $s d m 2$ was $3 \sim 4$ less than FH1. The number of branches $(P<0.05)$ and pods $(P>0.05)$ per plant was obviously more, while the 100 -pod weight and 100 -kernel weight were significantly decreased in $s d m 2(P<0.01)$.

To further accurately measure the change of mutant main stem height, we conducted hydroponic culture of $s d m 2$ and FH1 in Hogland solution. The length of each

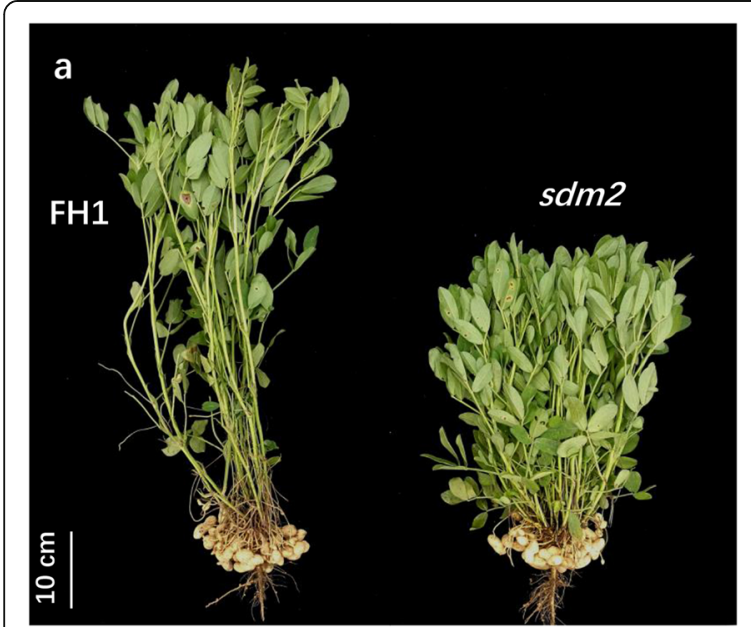

b
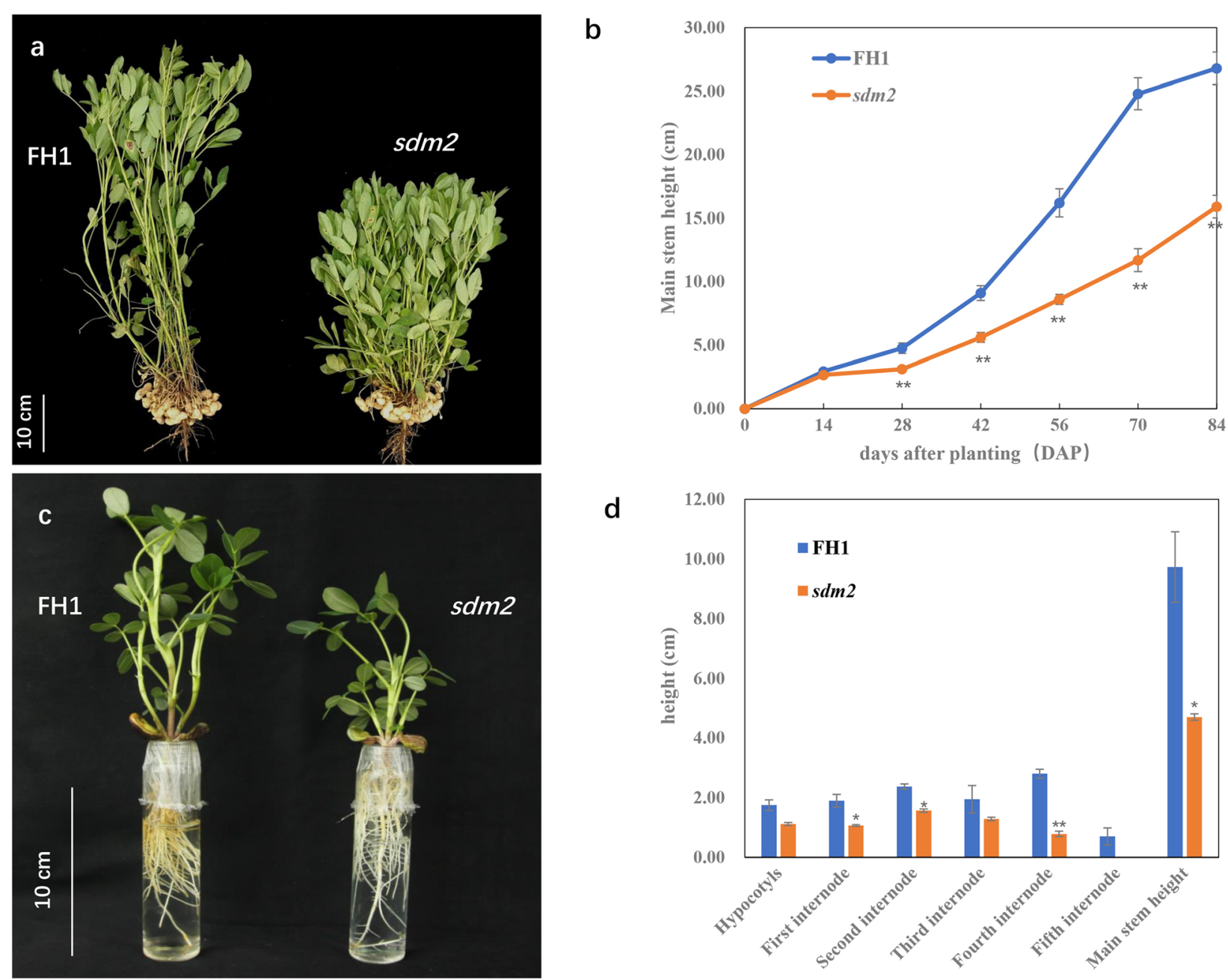

Fig. 1 Phenotypic characterization of sdm2 mutant and FH1. a Plants of sdm2 and FH1 at harvest time grown in the field; $\mathbf{b}$ Main stem height of sdm2 and FH1 at different growth stages grown in the field; c sdm2 and FH1 grown in Hogland solution for 14 DAP; d Main stem height measurement of sdm 2 and $\mathrm{FH} 1$ grown in Hogland solution for 14 DAP. Three biological replicates were used for statistical analysis (t-test; ${ }^{*} P<$ $\left.0.05,{ }^{* *} P<0.01\right)$. Values in $b, d$ represent means \pm SE $(n=3)$ 
internode and hypocotyl of 14 DAP seedlings were measured. We found that it was different from the results in experimental farm. For 14 DAP seedlings, the $s d m 2$ height was already significantly shorter than that of FH1 $(P<0.05)$ (Fig. 1c, d). There were total five internodes in FH1 and four in $s d m 2$ seedlings. The hypocotyl length of $s d m 2$ was slightly shorter than FH1 and there was no significant difference $(P>0.05)$ for the 14 DAP seedlings. The length of most internodes of $s d m 2$ was significantly shorter than FH1 (Fig. 1d). These results indicated that the height difference between $s d m 2$ and FH1 was caused by both reduced total number of internode and length of each internode.

\section{Sequencing data analysis}

To clarify global gene expression changes in $s d m 2,12$ cDNA libraries were constructed with stem and leaf from mutant and FH1 seedlings. The libraries were sequenced using BGISEQ-500 platform. A total of 0.26 billion raw reads were generated, and the average output of each sample was 21.7 million. After removing adaptor sequences, low-quality and N-containing reads, an average of 21.58 million clean reads were obtained from each library with the clean read ratio of $99.47 \%$ (Table 1). Approximately 19.27 million and 16.00 million clean reads in each library matched the reference genome and gene set perfectly with the average mapping ratio of 89.31 and $74.18 \%$, respectively. To investigate gene expression correlation among samples, the Pearson correlation coefficient of all gene expression levels between each two samples were calculated (Additional file 1: Fig. S1). It showed a higher correlation of similar tissue between $s d m 2$ and FH1. The principal component analysis (PCA) could clearly divide all samples into two clusters according to two kinds of tissues (Additional file 2: Fig. S2).

\section{DEGs between $s d m 2$ and $\mathrm{FH} 1$}

From all the samples, a total of 65,435 genes were identified. The gene expression of stem and leaf between sdm 2 and FH1 was analyzed, and 3733 and 3715 differentially expressed genes (DEGs) were identified, respectively (Additional files 3 and 4: Table S1 and S2). In $s d m 2$ stem, 1786 genes were up-regulated and 1947 genes were down-regulated to compare with FH1 (Fig. 2a and Additional file 3: Table S1). In $s d m 2$ leaf, the up- and down-regulated genes were 1644 and 2071, respectively (Fig. 2a and Additional file 4: Table S2). The majority of DEGs had different expression pattern in stem and leaf. Among 3733 DEGs in stem, only 873 were also differentially expressed in leaf. There were 473 down-regulated and 163 up-regulated DEGs with the same change trend in stem and leaf. It is worth noting that the number of common down-regulated DEGs was obviously higher than that of up-regulated ones. Interestingly, a large number of DEGs showed opposite expression pattern in stem and leaf. For example, there were 149 genes downregulated in mutant stem while up-regulated in leaf and 88 genes up-regulated in mutant stem but downregulated in leaf (Fig. 2b).

\section{Functional analysis of DEGs}

GO classification showed that 1724 DEGs from stem and 1716 DEGs from leaf were classified into three categories: biological process, cellular component, and molecular function (Fig. 3 and Additional file 5: Table S3). In molecular function category, catalytic activity and binding were the most abundant terms. For cellular component

Table 1 Summary of read numbers from stem and leaf in sdm2 and FH1

\begin{tabular}{|c|c|c|c|c|c|c|c|c|c|c|c|c|}
\hline \multirow[t]{2}{*}{ Sample name } & \multicolumn{6}{|c|}{ Reads in stem } & \multicolumn{6}{|c|}{ Reads in leaf } \\
\hline & $\begin{array}{l}\mathrm{FH} 1 \_S_{-} \\
1\end{array}$ & $\begin{array}{l}\text { FH1_S } \\
2\end{array}$ & $\begin{array}{l}\text { FH1_S } \\
3\end{array}$ & $\begin{array}{l}\text { sdm2 } \\
\text { S_1 }\end{array}$ & $\begin{array}{l}s d m 2_{-} \\
\text {s_2 }\end{array}$ & $\begin{array}{l}\text { sdm2_- } \\
\text { S_3 }\end{array}$ & $\begin{array}{l}\mathrm{FH} 1_{-} \mathrm{L}_{-} \\
1\end{array}$ & $\begin{array}{l}\text { FH1_L_ } \\
2\end{array}$ & $\begin{array}{l}\text { FH1_L_ } \\
3\end{array}$ & $\begin{array}{l}s d m 2_{-} \\
L_{-} 1\end{array}$ & $\begin{array}{l}s d m 2_{-} \\
L \_2\end{array}$ & $\begin{array}{l}\text { sdm2 } \\
L_{-} 3\end{array}$ \\
\hline Total raw read(M) & 21.64 & 21.66 & 21.67 & 21.65 & 21.84 & 21.67 & 21.86 & 21.61 & 21.74 & 21.65 & 21.64 & 21.71 \\
\hline Total clean read(M) & 21.51 & 21.54 & 21.56 & 21.53 & 21.74 & 21.52 & 21.78 & 21.50 & 21.65 & 21.47 & 21.53 & 21.60 \\
\hline Clean read ratio(\%) & 99.41 & 99.46 & 99.48 & 99.48 & 99.56 & 99.30 & 99.60 & 99.51 & 99.60 & 99.19 & 99.50 & 99.49 \\
\hline Clean read q20(\%) & 98.25 & 98.22 & 98.16 & 98.20 & 98.06 & 98.07 & 98.27 & 98.15 & 98.21 & 98.31 & 98.11 & 98.24 \\
\hline Clean read q30(\%) & 90.52 & 90.37 & 90.10 & 90.36 & 89.52 & 89.81 & 90.28 & 90.06 & 90.11 & 90.76 & 89.85 & 90.29 \\
\hline $\begin{array}{l}\text { Total mapping genome } \\
\text { reads (M) }\end{array}$ & 20.34 & 20.53 & 20.72 & 20.56 & 20.82 & 20.15 & 17.95 & 17.05 & 19.40 & 19.03 & 16.41 & 18.30 \\
\hline $\begin{array}{l}\text { Total mapping genome } \\
\text { ratio(\%) }\end{array}$ & 94.56 & 95.33 & 96.09 & 95.49 & 95.79 & 93.63 & 82.42 & 79.30 & 89.60 & 88.65 & 76.20 & 84.70 \\
\hline $\begin{array}{l}\text { Total mapping gene reads } \\
\text { (M) }\end{array}$ & 16.93 & 16.75 & 17.45 & 17.17 & 17.32 & 16.46 & 14.63 & 14.24 & 15.77 & 16.41 & 13.93 & 15.02 \\
\hline Total mapping gene ratio (\%) & 78.69 & 77.77 & 80.95 & 79.73 & 79.65 & 76.51 & 67.17 & 66.24 & 72.86 & 76.45 & 64.68 & 69.56 \\
\hline
\end{tabular}

Note: $\mathrm{S}$ indicates stem, and $\mathrm{L}$ indicates leaf. Each sample has three replicates 


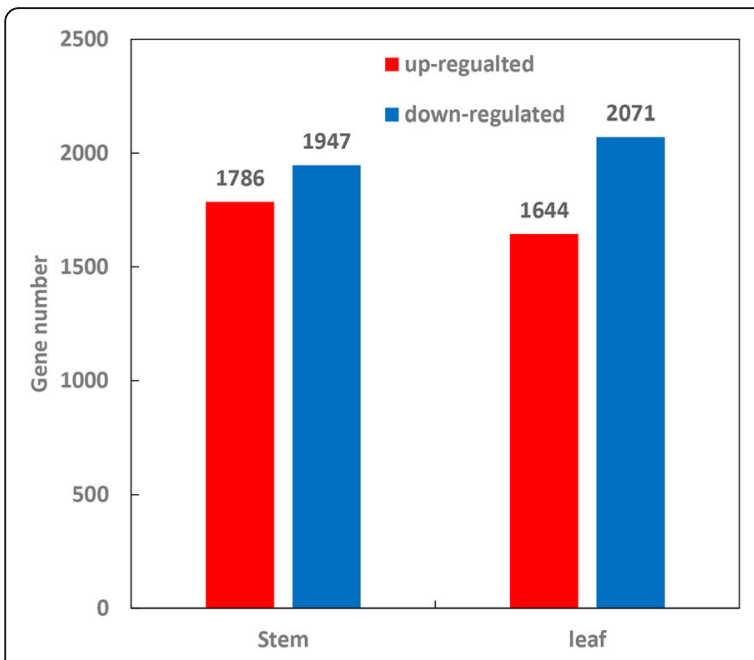

a

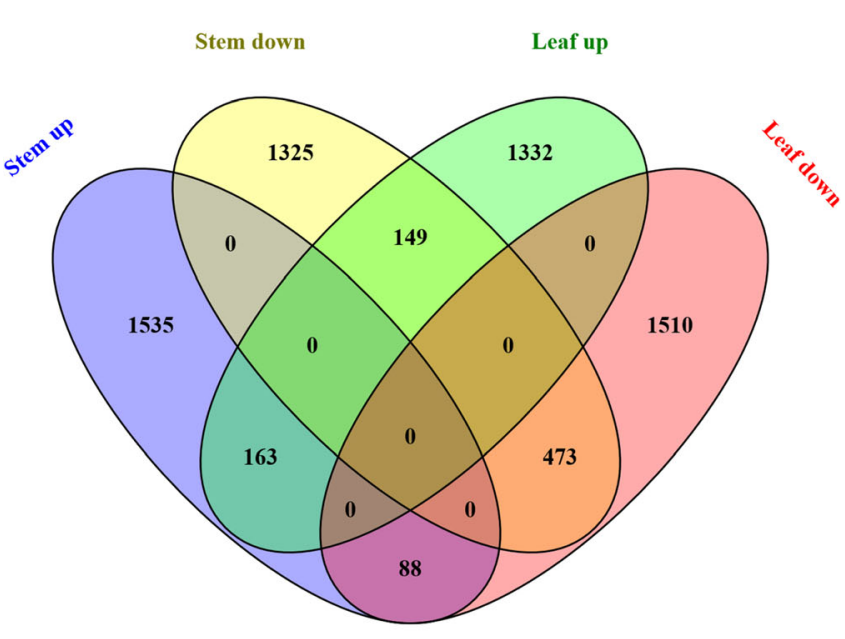

b

Fig. 2 Differentially expressed genes in sdm2 and FH1. a Numbers of differentially expressed genes in sdm2 and FH1; b Venn diagram showed the common and specific differentially expressed genes in stem and leaf

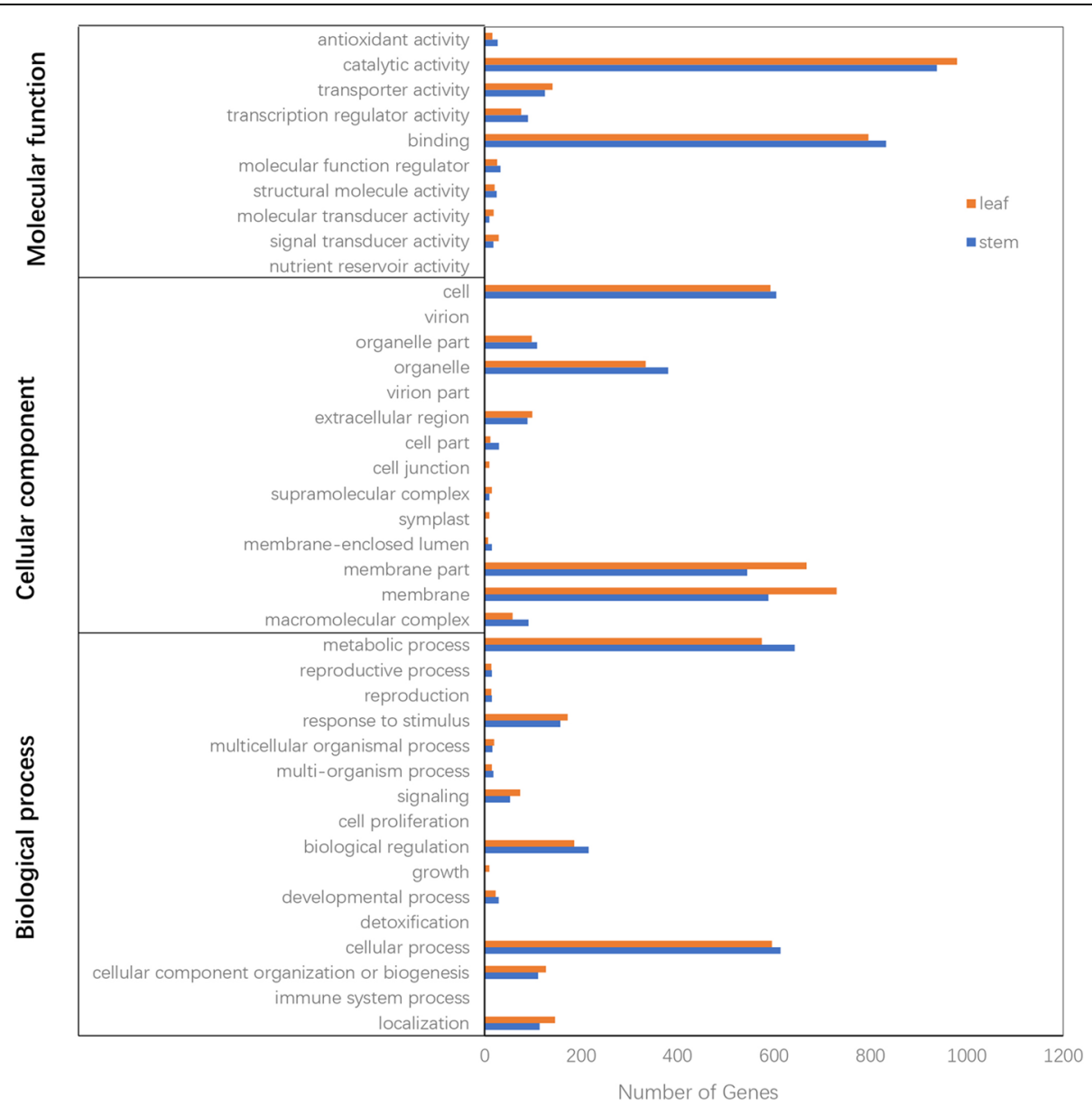

Fig. $3 \mathrm{GO}$ classification of DEGs in stem and leaf. The X-axis represents the number of genes annotated into the GO terms, and the Y-axis represents the functional classification 
category, cell, membrane, membrane part and organelle were the main terms. The top two terms of biological process were metabolic process and cellular process. The top 20 terms in stem and leaf were shown in Additional file 6: Fig. S3 and Additional file 7: Table S4.

KEGG pathway analysis was also carried out. According to the enrichment results, the top 20 pathways in stem and leaf were shown in Fig. 4 and Additional file 8: Table S5. In stem, many pathways involved in hormone biosynthesis and signal transduction including terpenoid backbone biosynthesis, monoterpenoid biosynthesis, diterpenoid biosynthesis, sesquiterpenoid and triterpenoid biosynthesis, zeatin biosynthesis, and brassinosteroid biosynthesis, indole alkaloid biosynthesis as well as plant hormone signal transduction were all enriched in the mutant (Fig. 4 and Additional file 8: Table S5). In addition, MAPK signaling pathway was also enriched. These results suggested that plant hormone play major roles in regulation of the mutant phenotype. There were other pathways including photosynthesis, phenylpropanoid biosynthesis, flavonoid biosynthesis, isoflavonoid biosynthesis, and flavone and flavonol biosynthesis pathways were found to be enriched.

In leaf, brassinosteroid biosynthesis, indole alkaloid biosynthesis, plant hormone signal transduction and MAPK signaling pathways were enriched in accordance with those in stem (Fig. 4 and Additional file 8: Table S5). Phenylpropanoid biosynthesis, flavonoid biosynthesis, isoflavonoid biosynthesis and plant-pathogen interaction were also in the top 20 enriched pathways. Different from that in stem, some glucide and glucolipid metabolic pathways were enriched in leaf.

\section{Cell wall related genes}

RNA-seq results showed that several CesA genes and all CSL genes were down-regulated in stem. The expression of most expansin genes was down-regulated in $s d m 2$ stem compared with those in FH1 (Fig. 5 and Additional file 3: Table S1). Interestingly, the expression of CesA, CSL and expansin genes was up-regulated in leaf (Fig. 5 and Additional file 4: Table S2). These results were coincided with the phenotype of $s d m 2$ leaf, dark green in color, thicker, smaller than FH1 leaf.

Some XTHs were significantly up-regulated and some were down-regulated in $s d m 2$ stem (Fig. 5 and Additional file 3: Table S1). In leaf, the expressions of all XTHs were up-regulated, and some XTHs were 16-fold higher than those in FH1 (Fig. 5 and Additional file 4: Table S2). Some genes encoding endo-1,4- $\beta$-glucanases (EGases) in stem and leaf were down-regulated.

\section{Expression changes of hormone biosynthesis and signaling genes}

DWF4 was designated as CYP90B1 and proposed to catalyze steroid $22 \alpha$-hydroxylation in BR biosynthesis [64]. A gene annotated as cytochrome P450 90B1 showed 73\% identity with Arabidopsis DWF4 gene, which play key roles in BR biosynthesis. In stem, the expression of this gene was detected in FH1, while not detected in $s d m 2$. In leaf, the expression of this gene in $s d m 2$ was also lower than that in FH1. Previous studies confirmed that cytochrome P450 monooxygenase CYP90A1 (CPD) acted as BR C-3 oxidase [36]. The expression level of CYP90A1 (CPD) in $s d m 2$ stem decreased by 1.2 -fold than that in FH1. While in leaf, its expression was slightly higher in $s d m 2$ than in FH1. The cytochrome P450 family members, CYP90C1/D1, CYP85 (Dwarf) and CYP71A1, mediate rate-limiting reactions in BR biosynthesis [65-67]. Our results showed that the expression of CYP90C1/D1 gene decreased by 2.64 -fold and 1.41-fold in stem and leaf respectively in $s d m 2$. The Dwarf genes which encoding cytochrome P450 85A-like in stem

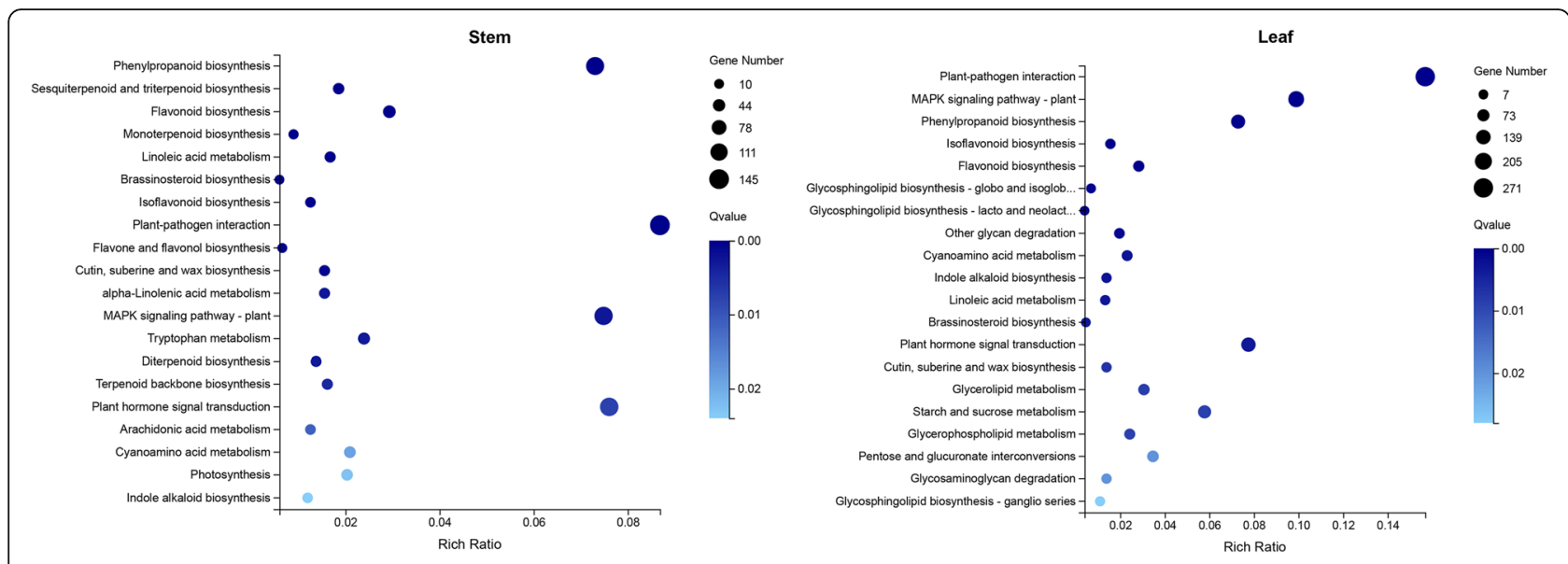

Fig. 4 Bubble diagram of top 20 enriched KEGG pathways of DEGs in stem and leaf. X axis represents the Rich Ratio, which meaning the ratio of selected gene number annotated to a particular item to the total number of genes in this item in one species. The calculating formula is Rich Ratio = Term Candidate Gene Num/Term Gene Num. Y axis represents KEGG Pathway. The size of the bubbles indicates the number of genes annotated to a KEGG Pathway. And the color represents Q-value of enrichment. The deeper the color, the smaller the Q-value 

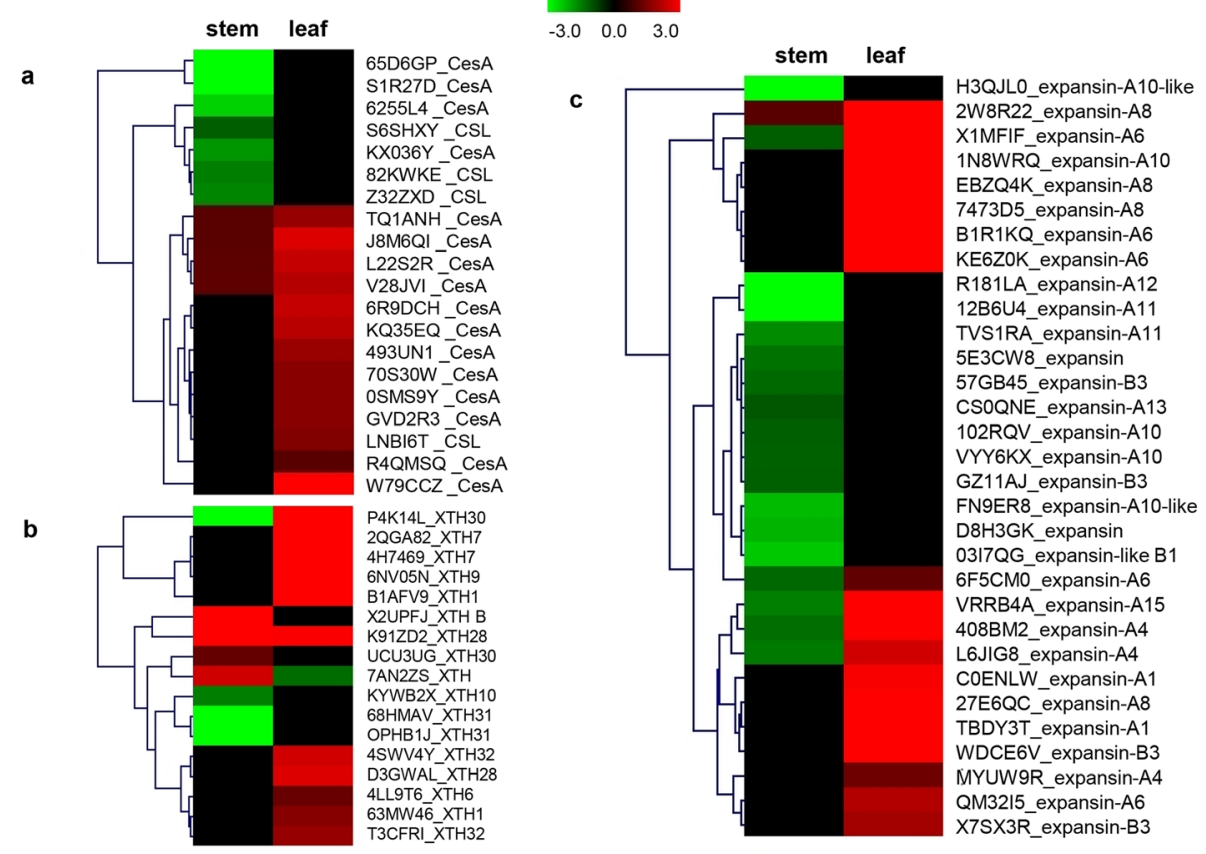

Fig. 5 The expression pattern of cell wall related genes in stem and leaf of sdm2. Heatmaps represent the differential expression of CesA and CSL $\mathbf{a}, X T H s \mathbf{b}$, expansions $\mathbf{c}$ in stem and leaf between sdm2 and FH1. Scale bar is located at upside with log2 ratio value varying from green to red

and cytochrome P450 85A in leaf were all up-regulated. CYP71A1 which catalyze the generation of deoxocastasterone (6-deoxoCS) and castasterone (CS) was downregulated both in stem and leaf in $s d m 2$. A cytochrome P450 monooxygenase (CYP734A1) which degrades BRs was up-regulated in $s d m 2$ leaf (Table 2, Additional files 3 and 4: Table S1 and S2).

In both stem and leaf, the expression levels of BRI1 and $B A K 1$ were down-regulated in $s d m 2$. Noticeably, the expression levels of $B E S 1 / B Z R 1$ gene were extremely low in stem and leaf in $s d m 2,170$-fold and 79-fold lower than in FH1, respectively. The expression levels of IWS1 in stem were up-regulated in $s d m 2$, while in leaf, it was not differentially expressed. The expression of cyclin-D3-3 encoding gene was down-regulated in $s d m 2$ stem, which was coincident with the expression trends of BR-related genes. While the expression levels of cyclin-D1 and cyclin-D5 increased in $s d m 2$ leaf (Table 2, Additional files 3 and 4: Table S1 and S2).

Several GA biosynthesis and signal transduction genes were differentially expressed between $s d m 2$ and FH1. In $s d m 2$, most of GA20ox and 2-oxoglutaratedependent dioxygenase encoding genes, which promote GA biosynthesis, were up-regulated in stem, while most 2-oxoglutarate-dependent dioxygenase decreased in leaf. While two genes encoding GA3ox were down-regulated in stem and its differential expression was not detected in leaf. GA2ox convert excess GAs to inactive forms through $2 \beta$-hydroxylation
[29]. In mutant stem and leaf, genes encoding GA2ox1 and GA2ox2 were decreased in expression levels while the expression of three genes encoding GA2ox8 were up-regulated in stem (Table 2, Additional files 3 and 4: Table S1 and S2).

Two GID1 genes in stem showed opposite change trend and one GID1 gene was down-regulated in leaf. SCL3 (Scarecrow-like 3) seemed to attenuate DELLA protein and acted as a positive regulator in GA pathway [68]. In mutant stem, SCL3 gene was up-regulated while two SCL14 and one SCL21 genes were down-regulated. Interestingly, all genes encoding gibberellin-regulated protein (GRP) were reduced in $s d m 2$ stem while upregulated in leaf, which were consistent with the change trends of cell wall related genes including CesA, CSL, expansin and XTH genes (Table 2, Additional files 3 and 4: Table S1 and S2).

Four $A U X 1$ genes in stem and two in leaf were all significantly up-regulated, while the expressional levels of two genes encoding auxin efflux carrier (PIN) in leaf decreased. In addition, the expression change trends of $M D R / A B C B$ genes in stem and leaf of $s d m 2$ were irregular, most of which were downregulated and some were up-regulated. In $s d m 2$ stem, two genes encoding AUX22 were down-regulated and almost all ARF members were up-regulated, while in leaf, the expressions of all $A u x / I A A$ and $A R F$ genes were increased. In addition, most SAUR genes in stem and almost all SAUR genes in leaf were up- 
Table 2 Differential expression of hormonal biosynthesis and signaling genes in stem and leaf between sdm2 and FH1

\begin{tabular}{|c|c|c|c|c|c|c|c|}
\hline \multirow[t]{2}{*}{ Gene ID } & \multirow[t]{2}{*}{ Nr Annotation } & \multirow[t]{2}{*}{ Gene name } & \multicolumn{4}{|c|}{ Relative expression level (sdm2/FH1) } & \multirow{2}{*}{$\begin{array}{l}\text { Expression } \\
\text { trend } \\
\text { (stem/leaf) }\end{array}$} \\
\hline & & & $\log _{2}($ stem $)$ & $\begin{array}{l}\text { Q-value } \\
\text { (stem) }\end{array}$ & $\log _{2}($ leaf $)$ & $\begin{array}{l}\text { Q-value } \\
\text { (leaf) }\end{array}$ & \\
\hline Arahy.MA1Z2D & cytochrome P450 90B1 & DWF4 & -9.35 & $2.43 \mathrm{E}-59$ & -3.99 & $1.29 \mathrm{E}-06$ & $\begin{array}{l}\text { down/ } \\
\text { down }\end{array}$ \\
\hline Arahy.66GL51 & cytochrome P450 90A1 isoform X1 & CPD & -1.31 & $9.68 \mathrm{E}-13$ & - & - & down/- \\
\hline Arahy.7AH9CA & 3-epi-6-deoxocathasterone 23-monooxygenase & CYP90C1/D1 & -2.40 & $2.29 \mathrm{E}-13$ & -1.59 & $2.47 \mathrm{E}-12$ & $\begin{array}{l}\text { down/ } \\
\text { down }\end{array}$ \\
\hline Arahy.31R89H & cytochrome P450 85A-like & Dwarf/BR6ox & 1.99 & $1.08 \mathrm{E}-07$ & - & - & up/- \\
\hline Arahy.JZF5VE & cytochrome P450 85A-like & Dwarf/BR6ox & 2.50 & $9.71 \mathrm{E}-13$ & - & - & up/- \\
\hline Arahy.27TAQT & cytochrome P450 85A & Dwarf/BR6ox & - & - & 2.16 & $4.98 \mathrm{E}-31$ & $-/$ up \\
\hline Arahy.2F8F1S & cytochrome P450 85A & Dwarf/BR6ox & - & - & 1.34 & $2.56 \mathrm{E}-35$ & $-/$ up \\
\hline Arahy.TI8LFW & cytochrome P450 71A1 & CYP71A & -1.81 & $0.00 E+00$ & -2.06 & $2.09 \mathrm{E}-53$ & $\begin{array}{l}\text { down/ } \\
\text { down }\end{array}$ \\
\hline Arahy.ZW245F & cytochrome P450 71A1-like & CYP71A & -1.63 & $3.04 \mathrm{E}-32$ & - & - & down/- \\
\hline Arahy.U2CXJI & cytochrome P450 734A1 & BAS1 & - & - & 1.80 & $\begin{array}{l}0.00 \mathrm{E}+ \\
00\end{array}$ & $-/$ up \\
\hline Arahy.GJFA3Z & $\begin{array}{l}\text { probable leucine-rich repeat receptor-like protein kin- } \\
\text { ase At5g49770 isoform X1 }\end{array}$ & BRI1 & -2.38 & $3.16 \mathrm{E}-51$ & - & - & down/- \\
\hline Arahy.56X5WL & $\begin{array}{l}\text { probable leucine-rich repeat receptor-like protein kin- } \\
\text { ase At5g49770 isoform X1 }\end{array}$ & BRI1 & -1.32 & $1.91 \mathrm{E}-44$ & - & - & down/- \\
\hline Arahy.BMJ2CS & $\begin{array}{l}\text { probable leucine-rich repeat receptor-like protein kin- } \\
\text { ase At1g35710 }\end{array}$ & BRI1 & - & - & -2.59 & $6.71 \mathrm{E}-07$ & -/down \\
\hline Arahy.69MPHZ & $\begin{array}{l}\text { probable leucine-rich repeat receptor-like protein kin- } \\
\text { ase At } 5 \mathrm{~g} 49770\end{array}$ & BRI1 & - & - & -2.49 & $7.76 \mathrm{E}-19$ & -/down \\
\hline Arahy.DH99G0 & $\begin{array}{l}\text { BRASSINOSTEROID INSENSITIVE 1-associated receptor } \\
\text { kinase } 1 \text {-like isoform X1 }\end{array}$ & BAK1 & -1.99 & 4.09E-07 & -2.08 & $2.39 \mathrm{E}-74$ & $\begin{array}{l}\text { down/ } \\
\text { down }\end{array}$ \\
\hline Arahy.SPI7HB & BES1/BZR1 homolog protein 2 & BES1/BZR1 & -8.42 & $0.00 E+00$ & -7.30 & $\begin{array}{l}0.00 \mathrm{E}+ \\
00\end{array}$ & $\begin{array}{l}\text { down/ } \\
\text { down }\end{array}$ \\
\hline Arahy.RCTC3C & BES1/BZR1 homolog protein 2 & BES1/BZR1 & -1.92 & 7.59E-08 & -1.20 & $1.08 \mathrm{E}-04$ & $\begin{array}{l}\text { down/ } \\
\text { down }\end{array}$ \\
\hline Arahy.ND2ZET & BES1/BZR1 homolog protein 2 & BES1/BZR1 & -1.94 & 4.11E-05 & - & - & down/- \\
\hline Arahy.22IVZ0 & gibberellin 20 oxidase 1-D & GA20ox & 5.77 & 3.55E-98 & - & - & up/- \\
\hline Arahy.B5269G & gibberellin 20 oxidase 1 -like & GA20ox & 1.64 & 8.35E-05 & - & - & up/- \\
\hline Arahy.Bし7SD & gibberellin 20 oxidase 2 & GA20ox & 5.60 & 4.62E-85 & - & - & up/- \\
\hline Arahy.YI9B6B & $\begin{array}{l}\text { probable 2-oxoglutarate-dependent dioxygenase } \\
\text { At5g05600 isoform X1 }\end{array}$ & $\begin{array}{l}\text { 2-oxoglutarate-dependent } \\
\text { dioxygenase }\end{array}$ & 1.39 & 2.07E-06 & 1.23 & $1.02 \mathrm{E}-04$ & up/up \\
\hline Arahy.XPP88F & 2-oxoglutarate-dependent dioxygenase AOP3 & $\begin{array}{l}\text { 2-oxoglutarate-dependent } \\
\text { dioxygenase }\end{array}$ & 1.08 & $9.86 \mathrm{E}-04$ & -1.90 & $4.14 \mathrm{E}-23$ & up/down \\
\hline Arahy.MT91AM & 2-oxoglutarate-dependent dioxygenase AOP3 & $\begin{array}{l}\text { 2-oxoglutarate-dependent } \\
\text { dioxygenase }\end{array}$ & 1.74 & $4.26 \mathrm{E}-07$ & - & - & up/- \\
\hline Arahy.K8MVYG & gibberellin 3-beta-dioxygenase 1 & GA30x & -1.41 & $1.18 \mathrm{E}-49$ & - & - & down/- \\
\hline Arahy.QH4I6C & gibberellin 2-beta-dioxygenase 1 isoform $\mathrm{X} 1$ & GA20x & -1.87 & $2.50 \mathrm{E}-04$ & -1.82 & $1.12 \mathrm{E}-11$ & $\begin{array}{l}\text { down/ } \\
\text { down }\end{array}$ \\
\hline Arahy.VR90R2 & gibberellin 2-beta-dioxygenase 8 & GA20x & 2.74 & $1.25 \mathrm{E}-17$ & - & - & up/- \\
\hline Arahy.EPT56A & gibberellin-regulated protein 11 & GRP11 & -1.84 & 1.80E-09 & - & - & down/- \\
\hline Arahy.F1TUFL & gibberellin-regulated protein 4 & GRP4 & -1.63 & $0.00 E+00$ & - & - & down/- \\
\hline Arahy.FJ610L & gibberellin-regulated protein 4 & GRP4 & - & - & 4.31 & $1.92 \mathrm{E}-70$ & $-/$ up \\
\hline Arahy.X9WA5F & PREDICTED: gibberellin-regulated protein 4 & GRP4 & -1.20 & $8.62 \mathrm{E}-115$ & 3.90 & $3.18 \mathrm{E}-37$ & down/up \\
\hline Arahy.VJ6NUA & gibberellin-regulated protein 6 isoform $\times 2$ & GRP6 & -1.44 & $1.83 \mathrm{E}-145$ & 3.75 & $5.91 \mathrm{E}-89$ & down/up \\
\hline Arahy.UA0Z8F & auxin transporter-like protein 1 & AUX1/LAX family & 6.46 & $2.83 \mathrm{E}-11$ & 4.70 & $1.25 \mathrm{E}-15$ & up/up \\
\hline Arahy.JN7ZD3 & auxin transporter-like protein 1 & AUX1/LAX family & 3.59 & $1.64 \mathrm{E}-04$ & - & - & up/- \\
\hline Arahy.LRNE2N & auxin transporter-like protein 3 & AUX1/LAX family & - & - & 2.06 & $4.38 \mathrm{E}-72$ & $-/$ up \\
\hline Arahy.953E9B & auxin efflux carrier component 5 isoform $\mathrm{X} 1$ & PIN family & - & - & -3.06 & $3.04 \mathrm{E}-06$ & -/down \\
\hline Arahy.K2GLG1 & auxin efflux carrier component 5 isoform $\mathrm{X} 1$ & PIN family & - & - & -1.36 & $2.22 \mathrm{E}-09$ & -/down \\
\hline
\end{tabular}


Table 2 Differential expression of hormonal biosynthesis and signaling genes in stem and leaf between sdm2 and FH1 (Continued)

\begin{tabular}{|c|c|c|c|c|c|c|c|}
\hline \multirow[t]{2}{*}{ Gene ID } & \multirow[t]{2}{*}{ Nr Annotation } & \multirow[t]{2}{*}{ Gene name } & \multicolumn{4}{|c|}{ Relative expression level (sdm2/FH1) } & \multirow{2}{*}{$\begin{array}{l}\text { Expression } \\
\text { trend } \\
\text { (stem/leaf) }\end{array}$} \\
\hline & & & $\log _{2}($ stem $)$ & $\begin{array}{l}\text { Q-value } \\
\text { (stem) }\end{array}$ & $\log _{2}($ leaf $)$ & $\begin{array}{l}\text { Q-value } \\
\text { (leaf) }\end{array}$ & \\
\hline Arahy.BB2RVD & ABC transporter B family member 19-like & ABCB subfamily & 3.17 & $1.24 \mathrm{E}-04$ & 1.27 & 3.06E-04 & up/up \\
\hline Arahy.RLV4PD & ABC transporter $B$ family member 1 & ABCB subfamily & - & - & 3.48 & 2.67E-09 & $-/$ up \\
\hline Arahy.M63M99 & ABC transporter B family member 11 & ABCB subfamily & - & - & -1.27 & $2.65 E-33$ & $-/$ down \\
\hline Arahy.YCYQ9Q & uncharacterized protein LOC107461514 & ABCB subfamily & -5.97 & $7.24 \mathrm{E}-43$ & -7.49 & $2.35 E-72$ & $\begin{array}{l}\text { down/ } \\
\text { down }\end{array}$ \\
\hline Arahy.M4RITN & uncharacterized protein LOC107461514 & ABCB subfamily & -5.13 & 2.19E-18 & -3.56 & 5.47E-04 & $\begin{array}{l}\text { down/ } \\
\text { down }\end{array}$ \\
\hline Arahy.8QDS11 & auxin-induced protein AUX22-like & Aux/IAA protein & -2.12 & $5.87 \mathrm{E}-54$ & 1.18 & $2.98 \mathrm{E}-30$ & down/up \\
\hline Arahy.KRC5M1 & auxin-induced protein AUX22 & Aux/IAA protein & -1.52 & $3.07 E-35$ & 1.34 & $3.65 E-35$ & down/up \\
\hline Arahy.2A4XC9 & $\begin{array}{l}\text { LOW QUALITY PROTEIN: auxin-responsive protein } \\
\text { IAA29 }\end{array}$ & Aux/IAA protein & 1.69 & $9.56 \mathrm{E}-15$ & 1.79 & $1.13 \mathrm{E}-09$ & up/up \\
\hline Arahy.S4Y3WA & auxin response factor 5 isoform $\mathrm{X} 2$ & ARF & 2.95 & $2.80 \mathrm{E}-24$ & 2.97 & 1.67E-04 & up/up \\
\hline Arahy.1B1167 & putative auxin response factor 23 & ARF & 2.15 & 4.14E-10 & - & - & up/- \\
\hline Arahy.X5Q10C & auxin response factor 18 -like isoform $\mathrm{X} 2$ & ARF & - & - & 5.44 & $5.42 \mathrm{E}-06$ & $-/$ up \\
\hline Arahy.MJW2EP & auxin-induced protein 15A-like & SAUR family & 1.86 & $2.74 \mathrm{E}-04$ & 6.59 & $5.68 \mathrm{E}-12$ & up/up \\
\hline Arahy.E8WPL7 & auxin-induced protein 6B-like & SAUR family & 1.26 & 4.39E-05 & 2.93 & 2.63E-08 & up/up \\
\hline Arahy.W3E9BL & auxin-responsive protein SAUR50-like & SAUR family & -1.11 & $3.81 \mathrm{E}-13$ & 3.98 & $1.86 \mathrm{E}-07$ & down/up \\
\hline Arahy.NWIK25 & indole-3-acetic acid-induced protein ARG7-like & SAUR family & - & - & 4.77 & 2.09E-07 & $-/$ up \\
\hline Arahy.G43XWA & protein SHORT INTERNODES-like & $\mathrm{SHI}$ & -6.32 & $1.91 \mathrm{E}-10$ & -6.63 & $3.98 \mathrm{E}-12$ & $\begin{array}{l}\text { down/ } \\
\text { down }\end{array}$ \\
\hline Arahy.F7N9UG & protein SHI RELATED SEQUENCE 3-like & SRS & 5.43 & $6.62 \mathrm{E}-06$ & - & - & up/- \\
\hline Arahy.ROGFR4 & protein SHI RELATED SEQUENCE 3-like & SRS & - & - & -6.63 & $3.98 \mathrm{E}-12$ & $-/$ down \\
\hline Arahy.EXJ5K8 & probable WRKY transcription factor 30 & WRKY30 & -1.20 & $7.10 \mathrm{E}-23$ & -3.09 & $1.42 \mathrm{E}-76$ & $\begin{array}{l}\text { down/ } \\
\text { down }\end{array}$ \\
\hline Arahy.TC7YOP & probable WRKY transcription factor 46 & WRKY46 & -1.39 & $5.50 \mathrm{E}-62$ & -1.96 & 1.75E-96 & $\begin{array}{l}\text { down/ } \\
\text { down }\end{array}$ \\
\hline Arahy.19PJJN & probable WRKY transcription factor 70 & WRKY70 & -2.64 & 4.37E-05 & -1.65 & $1.84 \mathrm{E}-26$ & $\begin{array}{l}\text { down/ } \\
\text { down }\end{array}$ \\
\hline Arahy.2031JR & transcription factor PRE6 & PRE6 & -2.41 & $5.06 \mathrm{E}-28$ & 2.91 & $6.65 \mathrm{E}-10$ & down/up \\
\hline Arahy. $577 \mathrm{H} 6 \mathrm{Y}$ & transcription factor PRE6 & PRE6 & -1.93 & $2.80 \mathrm{E}-07$ & 6.24 & 4.25E-36 & down/up \\
\hline Arahy.HR6FN8 & transcription factor PRE6 & PRE6 & -2.67 & $7.25 \mathrm{E}-71$ & & & down/- \\
\hline Arahy.YX8FPP & transcription factor PRE6-like & PRE6 & -2.33 & 5.39E-05 & & & down/- \\
\hline Arahy.WVIE7L & transcription factor PRE6 & PRE6 & - & - & 7.87 & $2.15 \mathrm{E}-50$ & $-/$ up \\
\hline
\end{tabular}

regulated in $s d m 2$ (Table 2, Additional files 3 and 4: Table S1 and S2).

\section{Transcription factors involved in plant growth and development}

Our results showed that several transcription factor genes involved in hormone signaling pathways and their downstream changed significantly. Gene encoding SHORT INTERNODES-like protein was downregulated both in stem and leaf of $s d m 2$. Whereas, SHI-RELATED SEQUENCE 3-like (SRS) gene increased in stem and decreased in leaf. All WRKY30/ $46 / 70$ genes were down-regulated in $s d m 2$ stem and leaf. The expression levels of four PRE6 genes decreased in stem and three PRE6 genes were up- regulated in leaf (Table 2, Additional files 3 and 4: Table S1 and S2).

\section{Verification of DEGs using qRT-PCR}

In order to validate the RNA-Seq data, the expression levels of DEGs were detected using Quantitative Realtime PCR (qRT-PCR). A total of 10 genes related to hormone signal transduction and cell wall organization were selected (Fig. 6 and Additional file 9: Table S6). The relative expression levels $\left(\log _{2} s d m 2 / F H 1\right)$ of these genes estimated by qRT-PCR were generally consistent with those by RNA-seq. The overall correlation coefficient of a liner regression analysis in stem and leaf was 0.7737 and 0.8328 , respectively (Fig. 6). 


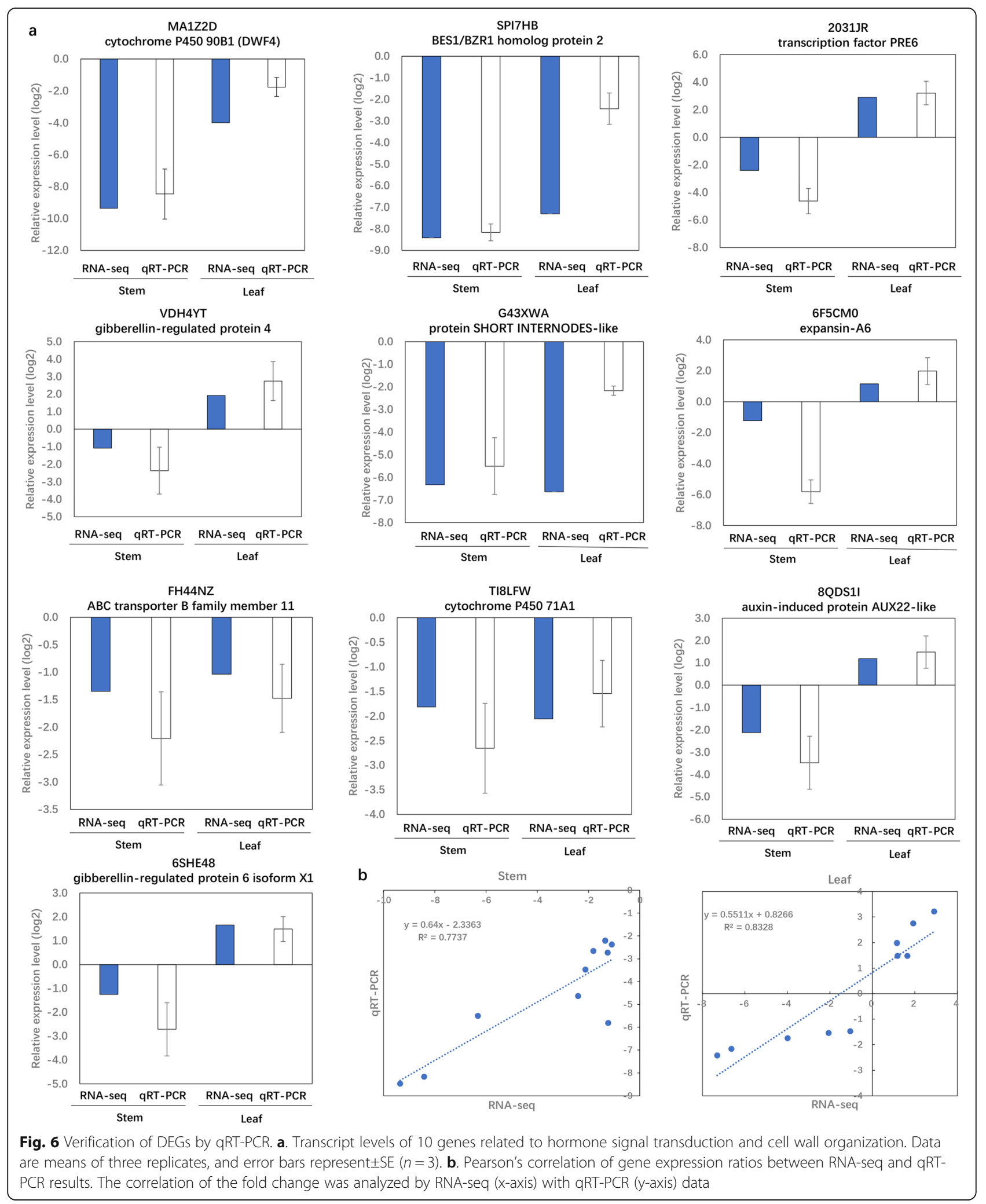

\section{Discussion}

Extensive studies indicated that deficiencies in cell wallrelated genes, GA, BR and IAA signaling pathways all could result in dwarfish. These deficient mutants displayed dwarf or semi-dwarf phenotype with shorter hypocotyl or internode, smaller and dark-green leaves 
[4-7, 20-23, 40, 50, 69]. Microscopic assays indicated that the dwarf phenotypes of BR-deficient and BRinsensitive mutants were caused by reduced cell size [23, 32]. Maize br2 mutant, deficient in the polar auxin transport, showed reduced stalk cell length and diameter [69]. In our study, $s d m 2$ phenotype was resulted from reduction both in internode number and internode length. The difference might be due to changes in cell division and cell expansion during the stem growth process, which was supported by the identification of a number of cell wall biosynthesis and metabolism enzyme encoding genes as DEGs. Cell division and cell expansion need the biogenesis or remodeling of cell wall. The extensibility of cell wall controls the rate of cell expansion. Genes, including CesA and CSL, responsible for cell-wall biogenesis, and expansins and XTHs, involved in cell wall loosening, are all critical in plant growth and development. Our transcriptome data revealed several CesAs, almost all CSLs and expanin genes were downregulated in $s d m 2$ stem. Some XTHs were downregulated in $s d m 2$ stem. Besides, genes encoding EGases which functions in the modification of hemicellulose network were down-regulated in $s d m 2$ stem. These results suggested that the cell wall biosynthesis and extensibility were reduced in $s d m 2$ stem, which might result in reduced cell division and cell expansion and further cause short internode and small number of stem nodes.

Studies revealed that many cell wall organization enzymes, including CesA, XTHs, EGases, and expansins were regulated by BRs [24, 45, 48, 70-72]. The essential roles of BRs in stem elongation have been confirmed by several mutants deficient in BR biosynthesis or perception $[23,30-32,40]$. Our results showed that key BR biosynthetic genes CPD, DWF4 and CYP90C1/D1 and CYP71A1 were all down-regulated in $s d m 2$. CYP734A1, which degrades BRs, was up-regulated in leaf of $s d m 2$. The changing trends of above genes suggested the contents of BRs might be decreased in $s d m 2$. BR response genes including $B R I 1, B A K 1$ and $B E S 1 / B Z R 1$, were down-regulated, especially $B E S 1 / B Z R 1$ in $s d m 2$ stem. These results suggested that BRs could be a key factor in the formation of semidwarf phenotype of $s d m 2$. In addition, BR signaling pathway also regulate the leaf and seed size and shape. In Arabidopsis cpd mutant, the decrease of cell size and cell number resulted in reduced leaf size [73]. The seeds of Arabidopsis $\operatorname{det} 2$ mutant were smaller and shorter because of decreased seed cavity, reduced endosperm volume and cell length and delayed embryo development [74]. Transgenic Arabidopsis and tobacco lines overexpressing DWF4 displayed increased plant height, longer petiole and leaf blade length, increased number of branches and siliques compared to the control [75]. In this study, $s d m 2$ plants showed smaller leaf size, shorter petiole, and both decreased seed size and weight, which were all in accordance with phenotypic characteristics of BR-deficient mutants. We speculate that CPD, DWF4, BRI1 and BES1/BZR1 are key genes that lead to the phenotypic differences between $s d m 2$ and FH1 line.

In this study, several GA biosynthetic genes showed irregular change trends and some seemed to promote the biosynthesis of GAs, while all GRP genes decreased in $s d m 2$ stem which had the same expressional pattern with those of cell wall related genes. This result could be a reflection of lowered GA level in $s d m 2$ stem, and the up-regulated expression of GA20ox and 2-oxoglutaratedependent dioxygenases might be resulted from the feedback regulation of GA signal pathway. The polar transport of auxin was essential for plant growth and development. In $s d m 2$, the increased transcription of auxin influx carrier and down-regulation of auxin efflux carrier together with the irregular changes of auxin polar transporters, $M D R / A B C B$ genes, suggested the disordered auxin transport from shoot apex and young leaves to stem. It might contribute to the formation of short internode in $s d m 2$.

BRs could affect GA biosynthesis through positively regulating GA20ox expression [76]. DELLA protein could directly interact with BZR1 and inhibit its DNA binding ability, and the promotion of GAs on cell elongation require BZR1 or BRs [57]. Application of auxin could induce the expression of GA20ox and GA3ox while reduce the GA2ox transcript [77, 78]. Auxin and BRs also could interact with each other and synergistically regulate plant development $[79,80]$. Auxin could directly induce DWARF4 expression and BR biosynthesis [81]. In return, BRs influenced auxin redistribution through stimulating the expression of PIN genes [82]. There are complicated cross talk among hormones during plant growth and development. Our results suggested that the significantly down-regulated BR biosynthetic and response genes, low GA response and disordered auxin transport acted synergistically and contributed to the defects in $s d m 2$ stem growth.

As the common target genes of the core transcription module, PRE family factors connect external and endogenous signals with downstream cell elongation components together through an antagonistic cascade reaction. The expressions of PRE6 genes in $s d m 2$ stem and leaf were consistent with those of cell wall enzymes, which further proved the direct promotion effects of PRE on cell elongation. Tracing back to the upstream hormonal signals, the extremely low expression of BR biosynthetic and signal transduction genes and low GA signaling in $s d m 2$ stem all contributed to the down-regulation of $P R E$ genes, and subsequently reduced cell elongation factors which finally caused the semi-dwarf phenotype. Based on these results, we proposed a potential model regulating peanut stem development (Fig. 7). BRs, GAs and auxin signaling pathways interact cooperatively to influence PRE 


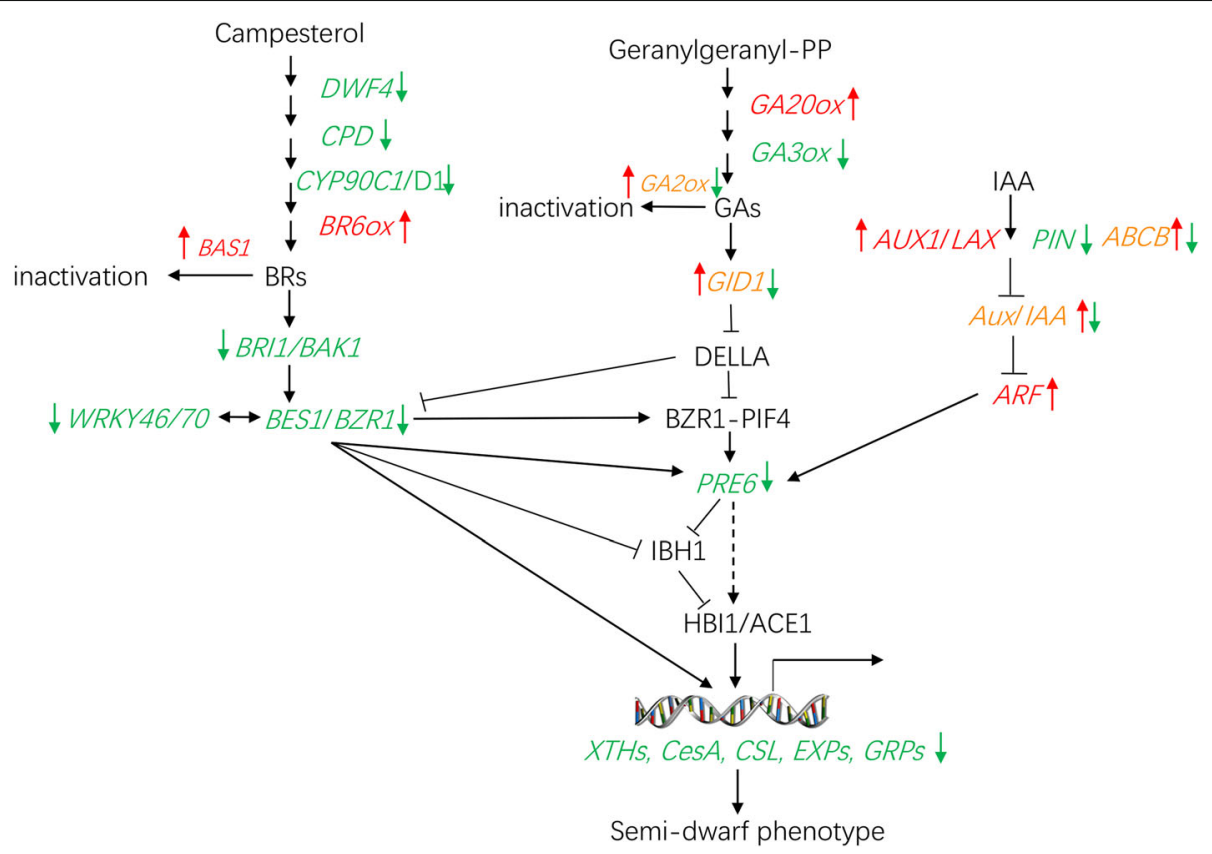

Fig. 7 The regulatory network underlying semi-dwarf phenotype in sdm2 mutant. DWF4: 22a-hydroxylase; CPD: putative C-3 oxidase; CYP90C1/ D1: 3-epi-6-deoxocathasterone 23-monooxygenase; BR6ox: Brassinosteroid-6-oxidases; BAS1: Brassinosteroids C-26 hydroxylase; BRI1: Brassinosteroid insensitive 1; BAK1:BRI1-associated receptor kinase 1; BES1: BRI1-EMS suppressor 1; BZR1: Brassinazole resistant 1; GA20ox: GA 20oxidases; GA3ox: GA 3-oxidases; GA2ox: GA 2-oxidases; GID1: GA-insensitive dwarf 1; DELLA: proteins containing conserved DELLA domains in the N terminus; PRE6: Paclobutrazol resistant 6; IBH1: ILI1 binding bHLH protein 1; HBI1: homolog of BEE2 interacting with IBH1; ACE1: activator for cell elongation 1; PHY: phytochrome; PIFs: phytochrome-interacting factors; AUX1/LAX: auxin1/like-AUX1; PIN:PIN-formed protein; ABCB: subfamily B of ATP-binding cassette; Aux/IAA: auxin resistant/indole-3-acetic acid inducible; ARF: auxin response factor; CesA: cellulose synthases; CSL: cellulose synthase-like genes; XTHs: xyloglucanendotransglucosylase/endohydrolases; EXPs: expansins; GRPs: gibberellin-regulated proteins

expression, and regulate downstream cell wall-related genes to control cell elongation during stem development. However, further research is required to verify this hypothesis after cloning the mutant gene.

\section{Conclusions}

The transcriptome analysis of $s d m 2$ identified a number of differentially expressed genes involved in hormone biosynthesis, signaling and cell wall synthetic and metabolic pathways. Especially several genes in BR pathway were significantly down-regulated in stem and leaf of $s d m 2$ as compared to FH1. Genes in cell wall synthetic and metabolic pathway which related to cell elongation were generally down-regulated in $s d m 2$ stem. These findings provide critical information for uncovering the molecular genetic control of peanut stem development.

\section{Methods}

\section{Plant materials}

The cultivated peanut cultivar Fenghua1 (FH1) was bred by and acquired from Yongshan Wan's laboratory in Shandong Agricultural University, Shandong Province of China. In 2013, the seeds of FH1 was irradiated with ${ }^{60} \mathrm{Co} \gamma$-ray of $500 \mathrm{~Gy}$. In $\mathrm{M}_{2}$ generation, a line with phenotypic segregation of normal and semi-dwarf plant height was screened. After self-crossing for another two generations, the stable semi-dwarf peanut line was obtained and named semi-dwarf mutant 2 (sdm2).

\section{Planting conditions and sampling methods}

In 2018, sdm2 and its wild type FH1 were sowed in experimental farm of Shandong Academy of Agricultural Sciences. The ridging mode was adapted with ridge spacing of $90 \mathrm{~cm}$, ridge width of $55 \mathrm{~cm}$ and ridge height of $12 \mathrm{~cm}$. Peanut seeds were sowed for two rows on each ridge with a single seed per hole, and the plant spacing and row spacing were $18 \mathrm{~cm}$ and $35 \mathrm{~cm}$, respectively. All field management followed the standard agricultural practices. For each line, about 100 plants were planted. It was sowed on May 1st and harvested on September 5th with the growing period of 129 days. The days after planting (DAP) was used to calculate seedling growth time. During the vegetative period, at least 5 plants from each line were selected to investigate the main stem height through measuring the length from base of the aboveground plant to the tip of the main stem for every 2 weeks. The 1 5 internodes and the first fully developed leaf were collected from 60 DAP plants of $s d m 2$ and FH1 for RNA sequencing. At this time, the main stem height of $s d m 2$ and FH1 was significantly different. The samples 
were frozen immediately in liquid nitrogen, and stored at $-80^{\circ} \mathrm{C}$ for RNA extraction. For both stem and leaf, three replicates were prepared.

The hydroponic culture experiment was conducted in illumination incubator in the laboratory. The temperature was $32{ }^{\circ} \mathrm{C}$ and the light-dark cycle was $14 \mathrm{~h}$ of light and $10 \mathrm{~h}$ of darkness. Seeds of $s d m 2$ and FH1 were planted in glass ware filled with Hogland culture solution with the preservative film for support. About 20 plants were planted for each line. At the 14 DAP, the number of internodes and the length of each internode and hypocotyl were measured. The main stem height was the summation of each internode length. Each line had five replicates.

\section{RNA extraction, CDNA synthesis and high throughput sequencing}

Total RNA was extracted from stem and leaf using Trizol Reagent (TaKaRa, Inc., Dalian, China) according to the manufacturer's instructions. RNA samples were treated with DNase I to remove genomic DNA contamination. RNA quality and quantity were analyzed using Agilent 2100 and NanoDrop. mRNA was enriched using magnetic beads with Oligo (dT) and cleaved into short fragments $(\sim 200 \mathrm{nt})$ in fragmentation buffer. The reverse transcription was conducted with random hexamer primer and then the second strand CDNA was synthesized. After end repair, the $5^{\prime}$ tails were phosphorylated, the $3^{\prime}$ tails were added with anadenine. Sequencing adaptors were ligated to the double-stranded DNA fragments. Then the fragments were amplified by PCR to construct cDNA library. The library was sequenced using BGISEQ-500 platform by Beijing Genomics Institute (BGI).

\section{Bioinformatics analysis of RNA-Seq data}

Raw reads were generated from each cDNA library. To obtain clean reads, the adaptor sequences, low-quality reads and reads containing more than $5 \%$ unknown bases were removed using SOAPunke and trimmomatic software. All clean reads were mapped to the reference genome of Arachis hypogaea cv. Tifrunner (https://www. peanutbase.org/data/public/Arachis_hypogaea/) using HISAT2 program [83]. The clean reads were aligned to reference gene by Bowtie2 (RNA-Seq by Expectation Maximization) [84]. The statistical analyses of randomness, degree of coverage, and sequencing saturation were also accomplished. The gene expression level was calculated with RSEM method [85] and normalized to FPKM (Fragments Per Kb per Million reads). The relative gene expression level between two samples was counted by $\log _{2}$ ratio. Pearson's correlation coefficient between every two samples and principal component analysis (PCA) were performed. Differentially expressed genes (DEGs) were identified using DEGseq2 method and screened with the criteria of fold change $\geq 2$ and Q-value $\leq 0.001$ [86].

Gene Ontology (GO) annotation was carried out by Blast2GO program through comparing DEGs with GO terms in the GO database and GO functional classification was performed using WEGO software. KEGG (Kyoto Encyclopedia of Genes and Genomes) pathway analysis was conducted by mapping DEGs to KEGG database. The GO and KEGG functional enrichment were performed using hypergeometric test. The $p$-value formula in hypergeometric test can be acquired from https://en.wikipedia. org/wiki/Hypergeometric_distribution in detail. FDR (False Discovery Rate) correction of all $p$-values was conducted. The GO terms and KEGG pathways whose FDR $\leq$ 0.01 were defined as significant enriched. BLASTX $(\mathrm{E}<$ 0.00001) against NCBI Nr database was carried out. For transcription factor (TF) annotation, the ORF of DEGs were detected by getorf software, then these ORFs were aligned to TF protein domain (data from PlantTFDB) using hmmsearch program, and finally TFs were identified according to the TF family characteristics described in PlantTFDB (http://plntfdb.bio.uni-potsdam.de/v3.0/). The DEGs were also aligned to Plant Resistance Gene Database (PRGdb, http://prgdb.crg.eu/) by DIAMOND software to identified the resistance genes according to the query coverage and identity. The heatmap of cell wall related gene expression was charted using $\mathrm{MeV}$ software (https://sourceforge.net/projects/mev-tm4/) with the data of relative gene expression level between two samples counted by $\log _{2}(s d m 2 / \mathrm{FH} 1)$.

\section{qRT-PCR validation of RNA-Seq data}

We used qRT-PCR method to verify the expressional levels of 10 selected genes. RNA samples were those used for high-throughput sequencing and the reverse transcriptions were performed using PrimeScript II 1st Strand cDNA Synthesis Kit (TaKaRa). The gene-specific primers were designed using PerlPrimer software and were listed in Additional file 10: Table S7. We performed qRT-PCR reaction on ABI7500 Real Time System (Applied Biosystems) using TB Green ${ }^{\text {Tu }}$ Premix Ex Taq ${ }^{\text {Th }}$ II (TaKaRa). The parameters of thermal cycle were $94{ }^{\circ} \mathrm{C}$ for $10 \mathrm{~min}$, followed by 40 cycles of $94^{\circ} \mathrm{C}$ for $15 \mathrm{~s}$ and $60^{\circ} \mathrm{C}$ for $1 \mathrm{~min}$ in a $20 \mu \mathrm{l}$ volume. Each reaction was performed three biological replications with actin gene as internal reference gene. The relative expressional level of each gene between $s d m 2$ and FH1 was calculated by $2^{-\Delta \Delta \mathrm{Ct}}$ method.

\section{Supplementary information}

Supplementary information accompanies this paper at https://doi.org/10. 1186/s12864-020-6614-0.

Additional file 1 Figure S1. The correlation heatmap of each sample of sdm2 and FH1. The $X$ and $Y$ axes represent each sample. The color 
represents the Pearson correlation coefficient (the darker the color, the higher the correlation; the lighter the color, the lower the correlation).

Additional file $\mathbf{2}$ Figure $\mathbf{S 2}$. The principal component analysis of each sample of sdm2 and $\mathrm{FH} 1$. X axis represents the principal component 1 and $Y$ axis represents the principal component 2.

Additional file $\mathbf{3}$ Table S1. Differentially expressed genes of stem between sdm2 and FH1

Additional file $\mathbf{4}$ Table S2. Differentially expressed genes of leaf between sdm2 and $\mathrm{FH} 1$.

Additional file $\mathbf{5}$ Table S3. GO classification of DEGs in stem and leaf. Additional file 6 Figure S3. Bubble diagram of top 20 enriched $\mathrm{GO}$ terms of DEGs in stem and leaf. $X$ axis represents the Rich Ratio, which meaning the ratio of selected gene number annotated to a particular item to the total number of genes in this item in one species. The calculating formula is Rich Ratio = Term Candidate Gene Num/Term Gene Num. $Y$ axis represents $G O$ Term. The size of the bubbles indicates the number of genes annotated to a GO Term. And the color represents Qvalue of enrichment. The deeper the color, the smaller the Q-value.

Additional file $\mathbf{7}$ Table S4. The top 20 enriched GO terms of DEGs in stem and leaf.

Additional file 8 Table S5. The top 20 enriched KEGG pathways of DEGs in stem and leaf.

Additional file 9 Table S6. Validation of RNA-seq results via qRT-PCR. Additional file $\mathbf{1 0}$ Table S7. Primers for qRT-PCR analysis.

\section{Abbreviations}

ABCB: Subfamily B of ATP-binding cassette; ACE1: Activator for cell elongation 1; ARF: Auxin response factor; Aux/IAA: Auxin resistant/indole-3acetic acid inducible; AUX1/LAX: Auxin1/like-AUX1; BAK1: BRI1-associated receptor kinase 1; BAS1: Brassinosteroids C-26 hydroxylase; BES1: BRI1-EMS suppressor 1; BR6ox: Brassinosteroid-6-oxidases; BRI1: Brassinosteroid insensitive 1; BZR1: Brassinazole resistant 1; CesA: Cellulose synthases: CPD: Putative C-3 oxidase; CSL: Cellulose synthase-like genes; CYP90C1/D1: 3epi-6-deoxocathasterone 23-monooxygenase; DELLA: Proteins containing conserved DELLA domains in the N terminus; DWF4: 22a-hydroxylase; EXPs: Expansins; GA20ox: GA 20-oxidases; GA20x: GA 2-oxidases; GA3ox: GA 3-oxidases; GID1: GA-insensitive dwarf 1; GRPs: Gibberellin-regulated proteins; HBI1: Homolog of BEE2 interacting with IBH1; IBH1: ILI1 binding bHLH protein 1; PCA: Principal component analysis; PHY: Phytochrome; PIFs: Phytochrome-interacting factors; PIN: PIN-formed protein; PRE6: Paclobutrazol resistant 6; qRT-PCR: Quantitative Real-time PCR; SAUR: Small auxin up RNA; XTHs: Xyloglucanendotransglucosylase/ endohydrolases

\section{Authors' contributions}

YXZ, XJW and LH conceived and designed the study, FDG, JJM, LH, SHS, $G H L, C Z Z, H X, S Z Z$ and JBS performed the experiments. FDG and JJM analyzed the data and drafted the manuscript with LH. YXZ and XJW revised the manuscript. All authors read and approved the final manuscript.

\section{Funding}

This work was financially supported by grants from the National Natural Science Foundation of China (31861143009, 31500217, 31471526), Shandong Province Natural Science Foundation (ZR2017MC005), Shandong Provincial project for crop variety improvement and application (2016LZGC025, 2017LZN032), Shandong Provincial key research and development program(2018GSF121032), Agricultural scientific and technological innovation project of Shandong Academy of Agricultural Sciences (CXGC2018E13), Shandong Province Taishan Scholar Foundation. The funding bodies played no role in the design of the study and collection, analysis, and interpretation of data and in writing the manuscript.

\section{Availability of data and materials}

The RNA-seq data in this study were available at NCBI Short Read Archive with the accession number of SRP213768 (https://www.ncbi.nlm.nih.gov/ search/all/?term=SRP213768).
Ethics approval and consent to participate

Not applicable.

\section{Consent for publication}

Not applicable.

\section{Competing interests}

The authors declare that they have no competing interests.

\section{Author details}

${ }^{1}$ College of Life Science, Shandong Normal University, Jinan, People's Republic of China. 'Biotechnology Research Center, Shandong Academy of Agricultural Sciences, Shandong Provincial Key Laboratory of Crop Genetic Improvement, Ecology and Physiology, Jinan, People's Republic of China. ${ }^{3}$ Life Science College of Shandong University, Jinan 250100, People's Republic of China.

Received: 29 July 2019 Accepted: 24 February 2020

Published online: 05 March 2020

\section{References}

1. Monna L, Kitazawa N, Yoshino R, Suzuki J, Masuda H, Maehara Y, et al. Positional cloning of rice semidwarfing gene, sd-1: rice "green revolution gene" encodes a mutant enzyme involved in gibberellin synthesis. DNA Res. 2002:9(1):11-7.

2. Peng J, Richards DE, Hartley NM, Murphy GP, Devos KM, Flintham JE, et al. 'Green revolution' genes encode mutant gibberellin response modulators. Nature. 1999:400(6741):256-61.

3. Van Sandt VS, Suslov D, Verbelen JP, Vissenberg K. Xyloglucan endotransglucosylase activity loosens a plant cell wall. Ann Bot. 2007;100(7): 1467-73.

4. Arioli T, Peng L, Betzner AS, Burn J, Wittke W, Herth W, et al. Molecular analysis of cellulose biosynthesis in Arabidopsis. Science. 1998;279(5351): 717-20.

5. Fagard M, Desnos T, Desprez T, Goubet F, Refregier G, Mouille G, et al. PROCUSTE1 encodes a cellulose synthase required for normal cell elongation specifically in roots and dark-grown hypocotyls of Arabidopsis. Plant Cell. 2000;12(12):2409-24.

6. Burton RA, Gibeaut DM, Bacic A, Findlay K, Roberts K, Hamilton A, et al. Virus-induced silencing of a plant cellulose synthase gene. Plant Cell. 2000; 12(5):691-706

7. Li M, Xiong G, Li R, Cui J, Tang D, Zhang B, et al. Rice cellulose synthase-like D4 is essential for normal cell-wall biosynthesis and plant growth. Plant J. 2009;60(6):1055-69.

8. Ding Z, Lin Z, Li Q, Wu H, Xiang C, Wang J. DNL1, encodes cellulose synthase-like D4, is a major QTL for plant height and leaf width in rice (Oryza sativa L.). Biochem Biophys Res Commun. 2015:457(2):133-40.

9. Wang B, Smith SM, Li J. Genetic regulation of shoot architecture. Annu Rev Plant Biol. 2018:69:437-68.

10. Cosgrove DJ. Loosening of plant cell walls by expansins. Nature. 2000; 407(6802):321-6.

11. Choi D, Lee $Y$, Cho HT, Kende H. Regulation of expansin gene expression affects growth and development in transgenic rice plants. Plant Cell. 2003; 15(6):1386-98.

12. Cho HT, Cosgrove DJ. Altered expression of expansin modulates leaf growth and pedicel abscission in Arabidopsis thaliana. Proc Natl Acad Sci U S A. 2000;97(17):9783-8.

13. Zenoni S, Reale L, Tornielli GB, Lanfaloni L, Porceddu A, Ferrarini A, et al. Downregulation of the Petunia hybrida alpha-expansin gene PhEXP1 reduces the amount of crystalline cellulose in cell walls and leads to phenotypic changes in petal limbs. Plant Cell. 2004;16(2):295-308

14. Goh HH, Sloan J, Dorca-Fornell C, Fleming A. Inducible repression of multiple expansin genes leads to growth suppression during leaf development. Plant Physiol. 2012;159(4):1759-70.

15. Jan A, Yang G, Nakamura H, Ichikawa $H$, Kitano H, Matsuoka M, et al. Characterization of a xyloglucan endotransglucosylase gene that is upregulated by gibberellin in rice. Plant Physiol. 2004;136(3):3670-81.

16. Fry SC, Smith RC, Renwick KF, Martin DJ, Hodge SK, Matthews KJ. Xyloglucan endotransglycosylase, a new wall-loosening enzyme activity from plants. Biochem J. 1992;282(Pt 3):821-8. 
17. Thompson JE, Fry SC. Restructuring of wall-bound xyloglucan by transglycosylation in living plant cells. Plant J. 2001;26(1):23-34.

18. Han Y, Ban Q, Li H, Hou Y, Jin M, Han S, et al. DkXTH8, a novel xyloglucan endotransglucosylase/hydrolase in persimmon, alters cell wall structure and promotes leaf senescence and fruit postharvest softening. Sci Rep. 2016;6: 39155.

19. Llop-Tous I, Dominguez-Puigjaner E, Palomer X, Vendrell M. Characterization of two divergent endo-beta-1,4-glucanase cDNA clones highly expressed in the nonclimacteric strawberry fruit. Plant Physiol. 1999;119(4):1415-22.

20. King RW, Evans LT, Mander LN, Moritz T, Pharis RP, Twitchin B. Synthesis of gibberellin GA6 and its role in flowering of Lolium temulentum. Phytochemistry. 2003;62(1):77-82

21. Sakamoto T, Miura K, Itoh H, Tatsumi T, Ueguchi-Tanaka M, Ishiyama K, et al. An overview of gibberellin metabolism enzyme genes and their related mutants in rice. Plant Physiol. 2004;134(4):1642-53.

22. Fleet CM, Sun TP. A DELLAcate balance: the role of gibberellin in plant morphogenesis. Curr Opin Plant Biol. 2005;8(1):77-85.

23. Szekeres M, Nemeth K, Koncz-Kalman Z, Mathur J, Kauschmann A, Altmann T, et al. Brassinosteroids rescue the deficiency of CYP90, a cytochrome P450, controlling cell elongation and de-etiolation in Arabidopsis. Cell. 1996;85(2): 171-82.

24. Wang ZY, Nakano T, Gendron J, He J, Chen M, Vafeados D, et al. Nuclearlocalized BZR1 mediates brassinosteroid-induced growth and feedback suppression of brassinosteroid biosynthesis. Dev Cell. 2002;2(4):505-13.

25. Sasaki A, Ashikari M, Ueguchi-Tanaka M, Itoh H, Nishimura A, Swapan D, et al. Green revolution: a mutant gibberellin-synthesis gene in rice. Nature. 2002:416(6882):701-2.

26. Spielmeyer W, Ellis MH, Chandler PM. Semidwarf (sd-1), "green revolution" rice, contains a defective gibberellin 20-oxidase gene. Proc Natl Acad Sci U S A. 2002;99(13):9043-8.

27. Ueguchi-Tanaka M, Ashikari M, Nakajima M, Itoh H, Katoh E, Kobayashi M, et al. GIBBERELLIN INSENSITIVE DWARF1 encodes a soluble receptor for gibberellin. Nature. 2005;437(7059):693-8.

28. Chen Y, Hou M, Liu L, Wu S, Shen Y, Ishiyama K, et al. The maize DWARF1 encodes a gibberellin 3-oxidase and is dual localized to the nucleus and cytosol. Plant Physiol. 2014;166(4):2028-39.

29. Lo SF, Yang SY, Chen KT, Hsing Yl, Zeevaart JA, Chen LJ, et al. A novel class of gibberellin 2-oxidases control semidwarfism, tillering, and root development in rice. Plant Cell. 2008;20(10):2603-18.

30. Chory J, Peto C, Feinbaum R, Pratt L, Ausubel F. Arabidopsis thaliana mutant that develops as a light-grown plant in the absence of light. Cell. 1989;58(5): 991-9.

31. Klahre U, Noguchi T, Fujioka S, Takatsuto S, Yokota T, Nomura T, et al. The Arabidopsis DIMINUTO/DWARF1 gene encodes a protein involved in steroid synthesis. Plant Cell. 1998;10(10):1677-90,

32. Azpiroz R, Wu Y, LoCascio JC, Feldmann KA. An Arabidopsis brassinosteroid-dependent mutant is blocked in cell elongation. Plant Cell. 1998;10(2):219-30.

33. Youn JH, Kim TW, Joo SH, Son SH, Roh J, Kim S, et al. Function and molecular regulation of DWARF1 as a C-24 reductase in brassinosteroid biosynthesis in Arabidopsis. J Exp Bot. 2018;69(8):1873-86.

34. Li J, Nagpal P, Vitart V, McMorris TC, Chory J. A role for brassinosteroids in lightdependent development of Arabidopsis. Science. 1996;272(5260):398-401.

35. Anwar A, Liu Y, Dong R, Bai L, Yu X, Li Y. The physiological and molecular mechanism of brassinosteroid in response to stress: a review. Biol Res. 2018; 51(1):46

36. Ohnishi T, Godza B, Watanabe B, Fujioka S, Hategan L, Ide K, et al. CYP90A1/ CPD, a brassinosteroid biosynthetic cytochrome P450 of Arabidopsis, catalyzes C-3 oxidation. J Biol Chem. 2012;287(37):31551-60.

37. He Z, Wang ZY, Li J, Zhu Q, Lamb C, Ronald P, et al. Perception of brassinosteroids by the extracellular domain of the receptor kinase BRI1. Science. 2000;288(5475):2360-3.

38. Wang ZY, Seto H, Fujioka S, Yoshida S, Chory J. BRI1 is a critical component of a plasma-membrane receptor for plant steroids. Nature. 2001;410(6826): 380-3.

39. Kinoshita T, Cano-Delgado A, Seto H, Hiranuma S, Fujioka S, Yoshida S, et al. Binding of brassinosteroids to the extracellular domain of plant receptor kinase BRI1. Nature. 2005;433(7022):167-71.

40. Clouse SD, Langford M, MCMorris TC. A brassinosteroid-insensitive mutant in Arabidopsis thaliana exhibits multiple defects in growth and development. Plant Physiol. 1996;111(3):671-8.
41. Li J, Wen J, Lease KA, Doke JT, Tax FE, Walker JC. BAK1, an Arabidopsis LRR receptor-like protein kinase, interacts with BRI1 and modulates brassinosteroid signaling. Cell. 2002;110(2):213-22.

42. Nam KH, Li J. BRI1/BAK1, a receptor kinase pair mediating brassinosteroid signaling. Cell. 2002;110(2):203-12.

43. Wang X, Kota U, He K, Blackburn K, Li J, Goshe MB, et al. Sequential transphosphorylation of the BRI1/BAK1 receptor kinase complex impacts early events in brassinosteroid signaling. Dev Cell. 2008;15(2):220-35.

44. Li J, Nam KH. Regulation of brassinosteroid signaling by a GSK3/SHAGGYlike kinase. Science. 2002;295(5558):1299-301.

45. Yin Y, Wang ZY, Mora-Garcia S, Li J, Yoshida S, Asami T, et al. BES1 accumulates in the nucleus in response to brassinosteroids to regulate gene expression and promote stem elongation. Cell. 2002;109(2):181-91.

46. Yin $Y$, Vafeados D, Tao Y, Yoshida S, Asami T, Chory J. A new class of transcription factors mediates brassinosteroid-regulated gene expression in Arabidopsis. Cell. 2005;120(2):249-59.

47. He JX, Gendron JM, Sun Y, Gampala SS, Gendron N, Sun CQ, et al. BZR1 is a transcriptional repressor with dual roles in brassinosteroid homeostasis and growth responses. Science. 2005;307(5715):1634-8.

48. Li L, Ye H, Guo H, Yin Y. Arabidopsis IWS1 interacts with transcription factor BES1 and is involved in plant steroid hormone brassinosteroid regulated gene expression. Proc Natl Acad Sci U S A. 2010;107(8):3918-23.

49. Schenck D, Christian M, Jones A, Luthen $H$. Rapid auxin-induced cell expansion and gene expression: a four-decade-old question revisited. Plant Physiol. 2010;152(3):1183-5.

50. Noh B, Murphy AS, Spalding EP. Multidrug resistance-like genes of Arabidopsis required for auxin transport and auxin-mediated development. Plant Cell. 2001:13(11):2441-54.

51. Knauss $S$, Rohrmeier T, Lehle L. The auxin-induced maize gene ZmSAUR2 encodes a short-lived nuclear protein expressed in elongating tissues. J Biol Chem. 2003;278(26):23936-43.

52. Esmon CA, Tinsley AG, Ljung K, Sandberg G, Hearne LB, Liscum E. A gradient of auxin and auxin-dependent transcription precedes tropic growth responses. Proc Natl Acad Sci U S A. 2006;103(1):236-41.

53. Spartz AK, Lee SH, Wenger JP, Gonzalez N, Itoh H, Inze D, et al. The SAUR19 subfamily of SMALL AUXIN UP RNA genes promote cell expansion. Plant J. 2012;70(6):978-90.

54. Fridborg I, Kuusk S, Moritz T, Sundberg E. The Arabidopsis dwarf mutant shi exhibits reduced gibberellin responses conferred by overexpression of a new putative zinc finger protein. Plant Cell. 1999;11(6):1019-32.

55. Chen J, Nolan TM, Ye H, Zhang M, Tong H, Xin P, et al. Arabidopsis WRKY46, WRKY54, and WRKY70 transcription factors are involved in Brassinosteroid-regulated plant growth and drought responses. Plant Cell. 2017;29(6):1425-39.

56. Oh E, Zhu JY, Wang ZY. Interaction between BZR1 and PIF4 integrates brassinosteroid and environmental responses. Nat Cell Biol. 2012;14(8): 802-9.

57. Bai MY, Shang JX, Oh E, Fan M, Bai Y, Zentella R, et al. Brassinosteroid, gibberellin and phytochrome impinge on a common transcription module in Arabidopsis. Nat Cell Biol. 2012;14(8):810-7.

58. Zhang LY, Bai MY, Wu J, Zhu JY, Wang H, Zhang Z, et al. Antagonistic HLH/ bHLH transcription factors mediate brassinosteroid regulation of cell elongation and plant development in rice and Arabidopsis. Plant Cell. 2009; 21(12):3767-80

59. Ikeda M, Fujiwara S, Mitsuda N, Ohme-Takagi M. A triantagonistic basic helix-loop-helix system regulates cell elongation in Arabidopsis. Plant Cell. 2012;24(11):4483-97.

60. Bai MY, Fan M, Oh E, Wang ZY. A triple helix-loop-helix/basic helix-loophelix cascade controls cell elongation downstream of multiple hormonal and environmental signaling pathways in Arabidopsis. Plant Cell. 2012; 24(12):4917-29.

61. Huang L, Ren X, Wu B, Li X, Chen W, Zhou X, et al. Development and deployment of a high-density linkage map identified quantitative trait loci for plant height in peanut (Arachis hypogaea L.). Sci Rep. 2016;6: 39478

62. Li YJ, Li LZ, Zhang XR, Zhang K, Ma DC, Liu JQ, et al. QTL mapping and marker analysis of main stem height and the first lateral branch length in peanut (Arachis hypogaeal.). Euphytica. 2017;213, 57(2).

63. Lv J, Liu N, Guo J, Xu Z, Li X, Li Z, et al. Stable QTLs for Plant Height on Chromosome A09 Identified From Two Mapping Populations in Peanut (Arachis hypogaea L.). Front Plant Sci. 2018;9:684. 
64. Choe S, Dilkes BP, Fujioka S, Takatsuto S, Sakurai A, Feldmann KA. The DWF4 gene of Arabidopsis encodes a cytochrome P450 that mediates multiple 22alpha-hydroxylation steps in brassinosteroid biosynthesis. Plant Cell. 1998; 10(2):231-43.

65. Shimada Y, Fujioka S, Miyauchi N, Kushiro M, Takatsuto S, Nomura T, et al. Brassinosteroid-6-oxidases from Arabidopsis and tomato catalyze multiple C-6 oxidations in brassinosteroid biosynthesis. Plant Physiol. 2001;126(2): $770-9$.

66. Kim GT, Fujioka S, Kozuka T, Tax FE, Takatsuto S, Yoshida S, et al. CYP90C1 and CYP90D1 are involved in different steps in the brassinosteroid biosynthesis pathway in Arabidopsis thaliana. Plant J. 2005:41(5):710-21.

67. Kang JG, Yun J, Kim DH, Chung KS, Fujioka S, Kim Jl, et al. Light and brassinosteroid signals are integrated via a dark-induced small G protein in etiolated seedling growth. Cell. 2001;105(5):625-36.

68. Zhang ZL, Ogawa M, Fleet CM, Zentella R, Hu J, Heo JO, et al. Scarecrow-like 3 promotes gibberellin signaling by antagonizing master growth repressor DELLA in Arabidopsis. Proc Natl Acad Sci U S A. 2011; 108(5):2160-5

69. Multani DS, Briggs SP, Chamberlin MA, Blakeslee JJ, Murphy AS, Johal GS. Loss of an MDR transporter in compact stalks of maize br2 and sorghum dw3 mutants. Science. 2003;302(5642):81-4.

70. Yu X, Li L, Zola J, Aluru M, Ye H, Foudree A, et al. A brassinosteroid transcriptional network revealed by genome-wide identification of BESI target genes in Arabidopsis thaliana. Plant J. 2011;65(4):634-46.

71. Li L, Yu X, Thompson A, Guo M, Yoshida S, Asami T, et al. Arabidopsis MYB30 is a direct target of BES1 and cooperates with BES1 to regulate brassinosteroid-induced gene expression. Plant J. 2009;58(2):275-86.

72. Sun Y, Fan XY, Cao DM, Tang W, He K, Zhu JY, et al. Integration of brassinosteroid signal transduction with the transcription network for plant growth regulation in Arabidopsis. Dev Cell. 2010;19(5):765-77.

73. Zhiponova MK, Vanhoutte I, Boudolf V, Betti C, Dhondt S, Coppens F, et al. Brassinosteroid production and signaling differentially control cell division and expansion in the leaf. New Phytol. 2013;197(2):490-502.

74. Jiang WB, Huang HY, Hu YW, Zhu SW, Wang ZY, Lin WH. Brassinosteroid regulates seed size and shape in Arabidopsis. Plant Physiol. 2013;162(4): 1965-77.

75. Choe S, Fujioka S, Noguchi T, Takatsuto S, Yoshida S, Feldmann KA. Overexpression of DWARF4 in the brassinosteroid biosynthetic pathway results in increased vegetative growth and seed yield in Arabidopsis. Plant J. 2001;26(6):573-82.

76. Bouquin T, Meier C, Foster R, Nielsen ME, Mundy J. Control of specific gene expression by gibberellin and brassinosteroid. Plant Physiol. 2001;127(2): 450-8.

77. Ross JJ, O'Neill DP, Smith JJ, Kerckhoffs LH, Elliott RC. Evidence that auxin promotes gibberellin A1 biosynthesis in pea. Plant J. 2000;21(6):547-52.

78. Wolbang CM, Ross JJ. Auxin promotes gibberellin biosynthesis in decapitated tobacco plants. Planta. 2001;214(1):153-7.

79. Bao F, Shen J, Brady SR, Muday GK, Asami T, Yang Z. Brassinosteroids interact with auxin to promote lateral root development in Arabidopsis. Plant Physiol. 2004;134(4):1624-31.

80. Nemhauser JL, Mockler TC, Chory J. Interdependency of brassinosteroid and auxin signaling in Arabidopsis. PLoS Biol. 2004;2(9):E258.

81. Chung Y, Maharjan PM, Lee O, Fujioka S, Jang S, Kim B, et al. Auxin stimulates DWARF4 expression and brassinosteroid biosynthesis in Arabidopsis. Plant J. 2011;66(4):564-78.

82. Li L, Xu J, Xu ZH, Xue HW. Brassinosteroids stimulate plant tropisms through modulation of polar auxin transport in Brassica and Arabidopsis. Plant Cell. 2005;17(10):2738-53

83. Kim D, Langmead B, Salzberg SL. HISAT: a fast spliced aligner with low memory requirements. Nat Methods. 2015;12(4):357-60.

84. Langmead B, Salzberg SL. Fast gapped-read alignment with bowtie 2. Nat Methods. 2012;9(4):357-9.

85. Li B, Dewey CN. RSEM: accurate transcript quantification from RNA-Seq data with or without a reference genome. BMC Bioinformatics. 2011;12:323.

86. Wang $L$, Feng Z, Wang $X$, Wang $X$, Zhang X. DEGseq: an $R$ package for identifying differentially expressed genes from RNA-seq data. Bioinformatics. 2010;26(1):136-8.

\section{Publisher's Note}

Springer Nature remains neutral with regard to jurisdictional claims in published maps and institutional affiliations.

Ready to submit your research? Choose BMC and benefit from:

- fast, convenient online submission

- thorough peer review by experienced researchers in your field

- rapid publication on acceptance

- support for research data, including large and complex data types

- gold Open Access which fosters wider collaboration and increased citations

- maximum visibility for your research: over $100 \mathrm{M}$ website views per year

At BMC, research is always in progress.

Learn more biomedcentral.com/submissions 